NBER WORKING PAPER SERIES

\title{
LABOR MARKET INSTITUTIONS AND THE DISTRIBUTION OF WAGES: THE ROLE OF SPILLOVER EFFECTS
}

\author{
Nicole M. Fortin \\ Thomas Lemieux \\ Neil Lloyd \\ Working Paper 28375 \\ http://www.nber.org/papers/w28375 \\ NATIONAL BUREAU OF ECONOMIC RESEARCH \\ 1050 Massachusetts Avenue \\ Cambridge, MA 02138 \\ January 2021
}

This paper was first prepared for a conference in honor of John DiNardo held at the University of Michigan on September 28-29, 2018. David Card, Henry Farber, David Lee, Larry Mishel, and several workshop participants provided useful feedback on an earlier version of the paper. We would like to thank the Social Science and Humanities Research Council of Canada and the Bank of Canada Fellowship Program for research support. The views expressed herein are those of the authors and do not necessarily reflect the views of the National Bureau of Economic Research.

NBER working papers are circulated for discussion and comment purposes. They have not been peer-reviewed or been subject to the review by the NBER Board of Directors that accompanies official NBER publications.

(C) 2021 by Nicole M. Fortin, Thomas Lemieux, and Neil Lloyd. All rights reserved. Short sections of text, not to exceed two paragraphs, may be quoted without explicit permission provided that full credit, including $(\odot$ notice, is given to the source. 
Labor Market Institutions and the Distribution of Wages: The Role of Spillover Effects

Nicole M. Fortin, Thomas Lemieux, and Neil Lloyd

NBER Working Paper No. 28375

January 2021

JEL No. D31,J31,J51,J80

\section{ABSTRACT}

This paper examines the role of spillover effects of minimum wages and threat effects of unionization in changes in wage inequality in the United States between 1979 and 2017. A distribution regression framework is introduced to estimate both types of spillover effects. Threat effects double the contribution of de-unionization to the increase in male wage inequality. Spillover effects magnify the explanatory power of declining minimum wages to two-thirds of the increase in inequality at the bottom end of the female wage distribution.

Nicole M. Fortin

Vancouver School of Economics

University of British Columbia

6000 Iona Drive

Vancouver, BC V6T 1L4

Canada

and NBER

nicole.fortin@ubc.ca

Thomas Lemieux

Vancouver School of Economics

University of British Columbia

6000 Iona Drive

Vancouver, BC V6T 1L4

Canada

and NBER

thomas.lemieux@ubc.ca
Neil Lloyd

Vancouver School of Economics

University of British Columbia

6000 Iona Drive

Vancouver, BC V6T 1L4

Canada

neil_lloyd@outlook.com

A data appendix is available at http://www.nber.org/data-appendix/w28375 


\section{Introduction}

A vast literature has investigated the causes of substantial and continuing growth in wage and earnings inequality in the United States. Although most studies suggest that various forms of technological change are a leading explanation for these changes (see, e.g., Acemoglu and Autor 2011), other explanations such as changes in labor market institutions have been implicated. For instance, DiNardo, Fortin, and Lemieux (1996, DFL from hereinafter) show that the decline in the real value of the minimum wage during the 1980s helps accounts for a significant fraction of the growth in wage inequality at the bottom of the distribution during this period. Card (1996), Freeman (1993) and DFL show that the decline in unionization contributed to the rise in male wage inequality over the same period. Card, Lemieux, and Riddell $(2004,2018)$ and Firpo, Fortin, and Lemieux (2018) find that the continuing decline in unionization after the late 1980s accounts for some of the continuing growth in inequality, while Farber et al. (2020) reach a similar conclusion using data going back to the 1940s.

A critical limitation of the earlier literature is that it typically ignored potential spillover effects of institutional changes. These could magnify the impact of such changes on the wage distribution. In an influential study, Lee (1999) shows that accounting for spillover or "ripple" effects of the minimum wage on the wage of workers earning slightly above the minimum substantially increases the impact of the minimum wage on the wage distribution. Lee (1999) finds that the decline in the minimum wage can explain half of the increase in the standard deviation of log wages, and almost all of the increase in the 50-10 differential between 1979 and 1989 once spillover effects are taken into account. Lee's estimates of the contribution of the minimum wage to inequality growth are substantially larger than those of DFL, who ignore spillover effects, although they have been recently challenged by Autor, Manning, and Smith (2016). DFL find that declining minimum wages explain about a quarter (25\% for men and 30\% for women) of the increase in the standard deviation of log wages between 1979 and 1988 , and about $60 \%$ of the increase in the $50-10$ differential.

With a few exceptions, existing studies of the impact of de-unionization on wage inequality ignore possible spillover effects of unionization. The existing decompositions typically assume that the observed non-union wage structure provides a valid counterfactual for how union workers would be paid in the absence of unionization. However, it has long been recognized that union power, as measured by the unionization rate (or related indicators), may also influence wage setting in the nonunion sector (e.g., Lewis, 1963). In particular, non-union employers may seek to emulate the union wage structure to discourage workers from supporting unionization. This "threat effect" (Rosen, 1969) 
likely increases the equalizing effects of unionization by making non-union wages more similar to the more equally distributed ones observed in the union sector. Based on cross-country evidence, Freeman (1996) conjectures that failing to incorporate threat effects biases down existing estimates of the effect of de-unionization. Taschereau-Dumouchel (2020) reaches a similar conclusion by calibrating a search model of the U.S. economy.

Empirical evidence on the distributional impact of threat effects is limited by the challenge of finding exogenous sources of variation in the rate of unionization (the conventional measure of threat effects) across labor markets. Older studies such as Freeman and Medoff (1981), Moore et al. (1985), and Podbursky (1986) estimate threat effects by including the unionization rate in the relevant market (defined by industry, occupation, and geography) in a standard wage regression, but only make limited attempts at controlling for possible confounding factors. One exception is Farber (2005) who uses the passage of "right-to-work" (RTW) laws in the states of Idaho (1985) and Oklahoma (2001) as an arguably exogenous source of variation in union power. Unfortunately, Farber's results based on Current Population Survey (CPS) data are inconclusive because of a lack of statistical power linked to the small samples available in these two states. More recently, Farber et al. (2020) exploit cross-state variation linked to the National War Labor Board and the introduction of the Wagner Act to show that the unionization rate reduced wage dispersion in the middle of the $20^{\text {th }}$ century.

The contribution of this paper is twofold. First, we update DFL's analysis until 2017 to see whether changes in labor market institutions have remained an important source of inequality change over the last 25 years. Second, we extend DFL by taking into account spillover effects of the minimum wage and unionization. In the case of the minimum wage, we depart from Lee (1999) and Autor, Manning, and Smith (2016) by estimating a rich model of the wage distribution using distribution regressions (Foresi and Peracchi, 1995, Fortin and Lemieux, 1998, Chernozhukov et al., 2013). The model is analogous to a distributional difference-in-differences approach that yields estimates of spillover effects regardless of whether the minimum wage varies at the state or federal level.

We extend this framework to consider the case of union threat effects, which are estimated jointly with the effect of the minimum wage, allowing us to construct counterfactual wage distributions with and without minimum wage and union spillovers. Given the challenges of finding a suitable instrument for unionization, we proxy the threat effect using the unionization rate at the state-industry 
level, and include it as an additional regressor in the distribution regressions. ${ }^{1}$ A rich set of controls, including industry- and state-specific trends, are also included to control for other factors that could confound the relationship between wages and the rate of unionization. As in DFL, we also estimate the direct impact of unions using a "shift-share" analysis.

Our key findings are as follows. First, we estimate minimum wage spillover effects that are roughly as large as those found by Lee (1999) for the 1980s, though the magnitude of spillover effects is smaller in subsequent years. These differences partly reconcile the difference in results between Lee (1999) and Autor, Manning, and Smith (2016), who found smaller spillover effects using data for more recent years. Second, we find that minimum wage changes account for most of the substantial growth in lower tail inequality (50-10) in the 1980s, and its relative stability since then. Our main finding concerning unions is that spillover effects of unionization on non-union wages are similar in magnitude and distributional impact (shape) to the direct, or "shift-share", impact of unionization. The effects are largest in the lower middle of the distribution but negative at the top. Adding spillover effects roughly doubles the contribution of de-unionization to the growth in wage inequality. For instance, in the case of men, the contribution of unions to the steady growth in the 90-50 gap over the entire 1979-2017 period goes from $20 \%$ to $40 \%$ when spillover effects are taken into account. Overall, we find that changes in labor market institutions account for $53 \%$ and $28 \%$ of the $1979-2017$ growth in the standard deviation of log wages for men and women, respectively.

The remainder of the paper is organized as follows. In Section 2, we propose a distribution regression approach to estimate the minimum wage spillover effects. In Section 3, we discuss our strategy for measuring threat effects in a distributional context. We present the data and estimation results in Section 4 and use decompositions to compute the contribution of changing institutions to changes in the wage distribution in Section 5. We conclude in Section 6.

\section{Estimating spillover effects of the minimum wage}

A key contribution of DFL was to present visual evidence based on kernel density estimates to illustrate the role of the decline in the real value of the minimum wage in the growth of wage

\footnotetext{
${ }^{1}$ In an earlier version of the paper (Fortin, Lemieux, and Lloyd, 2019), we attempted to take advantage of the introduction of right-to-work laws in three large Midwestern states: Indiana (2011), Michigan (2013), and Wisconsin (2015). As in Farber (2005), we lacked statistical power to draw clear implications for wage inequality. Thus, we reverted to the traditional approach that proxies the threat of unionization with the state-industry specific unionization rate, as explained below.
} 
inequality between 1979 and 1988. DFL then made two main assumptions to quantify the contribution of the minimum wage to inequality growth. First, they assumed that the changes in the minimum wage did not affect employment. Card and Krueger (1995)'s contemporary work was used in support of the assumption of no employment effect. DFL also showed that allowing for modest employment effects had little impact on the findings. On the other hand, recent work by Brochu et al. (2018) based on Canadian data shows substantial spillover effects even after controlling for employment effects using a hazard rate estimation approach. Cengiz et al. (2019) find evidence that spillover effects easily counterbalance dis-employment effects using a "bunching" estimator implemented in a distributional event study approach. In light of this recent evidence, we ignore the minimum wage's possible employment effects in this study.

More importantly, DFL assumed that minimum wages had no spillover effects. This assumption allowed them to use a simple "tail pasting" approach where the bottom end of the distribution in a low minimum wage year (1988) is replaced by the corresponding bottom end of the distribution in a high minimum wage year (1979).

Lee (1999) relaxed the assumption of no spillover effects by exploiting the fact that a prevailing federal minimum wage is relatively higher in low-wage than high-wage states. His basic estimation approach consists of running flexible regressions of selected wages percentiles relative to the median on the relative value of the minimum wage by state and year. This involves running regressions of $w_{s t}^{q}-w_{s t}^{.5}$ on a polynomial function in $m w_{s t}-w_{s t}^{.5}$, where $w_{s t}^{q}$ is the $q^{\text {th }}$ percentile of log wages in state $s$ at time $t$, while $m w_{s t}$ is the corresponding value of the minimum wage. The term $m w_{s t}-w_{s t}^{5}$ measures the relative "bite" of the minimum wage in different states. The minimum wage "bites" more in low-wage states where $m w_{s t}-w_{s t}^{5}$ is larger than in high-wage states where it is lower. Using this approach, Lee finds that the minimum wage impacted wage percentiles above and beyond the corresponding value of the minimum wage. He concludes that changes in the minimum wage can explain most of the change in inequality in the lower tail of the distribution between 1979 and 1989, once spillover effects are taken into account.

This finding has been challenged by Autor, Manning, and Smith (2016) who point out that sampling error in the estimated median wage $w_{s t}^{5}$ can positively bias estimates of Lee-type regressions as the noisily measured median is included on both sides of the regression. They suggest correcting for this problem by instrumenting the right-hand side variable $m w_{s t}-w_{s t}^{5}$ with the value of the minimum wage $m w_{s t}$. As Lee-type regressions also include year dummies, this strategy can only work in periods 
where there is substantial variation in state minimum wages, given that time dummies fully absorb the variation in the federal minimum wage. Autor, Manning, and Smith (2016) take advantage of the substantial variation in state minimum wages after the 1980s (see Figure 1) to revisit Lee's estimates and find substantially smaller spillover effects.

One alternative interpretation of these findings is that Lee's estimates of spillover effects are not substantially biased, but they have become smaller over time. It is indeed unclear that the more frequent and smaller changes in state minimum wages of the post-1980s period have a comparable impact to the massive (over 30\%, see Figure 1) and permanent decline in the real value of the federal minimum wage that took place during the 1980s. Indeed, a large and permanent change in the minimum wage may affect the composition of firms at the lower end of the wage distribution. Butcher et al. (2012) argue that when firms have monopsony power, spillover effects can arise as unproductive firms shut down when the minimum wage increases and their workers move to more productive and higher-paying firms. ${ }^{2}$ Such a reallocation channel is unlikely to occur for smaller and more transitory changes in the minimum wages. Spillover effects may still arise because of internal wage considerations (Grossman, 1983, Dube et al., 2019), but the magnitude of these spillover effects may be smaller than when longer-term labor reallocation effects are involved. ${ }^{3}$

In what follows, we propose a new estimation approach based on distribution regressions that makes it possible to estimate minimum wage spillover effects regardless of whether the minimum wage varies at the state or federal level. Intuitively, Lee (1999) uses a two-step procedure by estimating distributional statistics like the median in a first step and plugging it in a regression model for wage percentiles in a second step. Autor, Manning, and Smith (2016) then propose an IV procedure to correct the bias from the noisy measure plugged into the second step estimation. By contrast, in our approach, we jointly estimate the wage distribution and the impact of the minimum wage in a single step. As a result, our approach does not yield biased results because of the estimated regressor problem.

\footnotetext{
${ }^{2}$ See also Haanwinckel (2020), who highlights a similar channel in a model where, as in Teulings (2000), firms differ in their task requirements but also have some monopsony power.

${ }^{3}$ See Brochu et al. (2018) for a more thorough discussion of possible economic explanations for minimum wage spillover effects, and Dustmann et al. (2020) for evidence of reallocation effects following the introduction of a nation-wide minimum wage in Germany.
} 


\subsection{Distribution regressions}

Following Foresi and Peracchi (1995) and Chernozhukov et al. (2013), we use a distribution regression approach to model the whole wage distribution and the effects of the minimum wage at different points of the distribution. The logic is straightforward. The probability of an outcome variable $Y$ being above (or below) a given cut-point $y_{k}$ is modeled as a flexible function of covariates $X$, and estimated using a probit, logit, or linear probability model. For example, in the case of a probit model we have:

$$
\operatorname{Prob}\left(Y \geq y_{k}\right)=\Phi\left(X \beta_{k}\right) \quad \text { for } k=1,2, \ldots, K
$$

The $y_{k}$ cutoffs can either be chosen using a fine grid or as percentiles $(k=1,2, \ldots, 99)$ of the unconditional wage distribution. The method is quite flexible as rich functions of the covariates, including state and year dummies, can be included as regressors, and no restrictions are imposed on how $\beta_{k}$ varies across cutoff values. Once the series of distribution regressions have been estimated, various counterfactual scenarios can be computed by either changing the distribution of the covariates or some of the $\beta_{k}$ coefficients.

However, the flexibility of these distribution regressions comes at a cost as there is no guarantee to get positive counterfactual probabilities, especially when the set of covariates is large. Furthermore, and as we discuss below, minimum wage effects are modeled by adding to the list of covariates a set of dummy variables indicating where the minimum wage stands (at, below, or above) relative to a given cutoff point $y_{k}$. Allowing for different minimum wage effects at each cutoff would be an overly flexible approach yielding identification challenges (see Section 2.3). For the same reason, Firpo, Fortin, and Lemieux (2009)'s RIF-regressions are not ideally suited to the estimation of minimum wage spillover effects. We instead propose a more parametric, though still flexible, approach where the impact of the minimum wage is modelled in a relatively parsimonious way. ${ }^{4}$ As we show in Section 4.2 below, doing so provides a better connection to the bunching analysis of Cenzig et al. (2019), and helps highlight the channels through which the minimum wage reshapes the wage distribution.

\footnotetext{
${ }^{4}$ Brochu et al. (2018) use a closely related method based on hazard functions instead of distribution regressions. For reasons explained below, a useful feature of our approach is that it is more directly connected to a latent skill index model of wage setting latent variables. That said, the two methods yield similar estimates of minimum wage spillover effects, which is re-assuring given the differences between the two methods.
} 
We impose restrictions on the $\beta_{k}$ coefficients by letting them evolve in a smooth way over the wage distribution. Doing so also helps provide an economic interpretation to the distribution regressions. For example, when the $\beta_{k}$ 's are fixed across the distribution, the model can be represented using a standard latent variable framework. Consider a latent $\log$ wage or skill index $Y^{*}=X \beta+\varepsilon$, where $\varepsilon \sim N(0,1)$. The observed wage is assumed to be a monotonic transformation $Y=g(X \beta+\varepsilon)$ of the skill index. Fortin and Lemieux (1998) call this model a "rank regression" as the main restriction imposed is that each observation's rank is the same in both the wage and skill distributions.

The model is flexibly estimated by dividing the wage range into a fine grid. Fortin and Lemieux (1998) use about 200 cutoff points $y_{k}$. The corresponding cutoff points in the skill distribution, $c_{k}$, are defined as $c_{k}=g^{-1}\left(y_{k}\right)$. It follows that:

$$
\operatorname{Prob}\left(Y \geq y_{k}\right)=\Phi\left(X \beta-c_{k}\right)
$$

This corresponds to a standard ordered probit model where the probability of observing wages in a wage category $\left[y_{k}, y_{k+1}\right]$ is given by:

$$
\operatorname{Prob}\left(y_{k} \leq Y<y_{k+1}\right)=\Phi\left(X \beta-c_{k+1}\right)-\Phi\left(X \beta-c_{k}\right)
$$

When the transformation function $g(\cdot)$ is linear, it follows that $Y=\sigma \cdot(X \beta+\varepsilon)=X \beta^{\prime}+u$, where $\beta^{\prime}=\sigma \beta$ and $u=\sigma \varepsilon$ is a homoskedastic normal error term with a standard deviation of $\sigma$. It also follows that the cutoff points in the ordered probit model, $c_{k}$, are a linear function $c_{k}=y_{k} / \sigma$ of the wage cutoffs $y_{k}$.

While log normality may not be a bad approximation of the conditional wage distribution, the homoskedasticity assumption is quite strong and clearly violated in wage data (see, e.g., Lemieux, 2006). For the rank regression model to fit the data reasonably well, it is essential to allow for heteroscedasticity in the error term $\varepsilon$. To see how this changes the probability model, consider a simple case where individuals belong to two education groups: high school $(X=0)$ and college $(X=1)$ graduates. Assume that log wages are normally distributed with a different mean and variance for each of the two groups: 


$$
\begin{aligned}
& Y=\beta_{0}+\varepsilon \text { with } \varepsilon \sim N\left(0, \sigma_{0}\right) \text { for } X=0, \text { and } \\
& Y=\beta_{1}+\varepsilon \text { with } \varepsilon \sim N\left(0, \sigma_{1}\right) \text { for } X=1 .
\end{aligned}
$$

It follows that

$$
\begin{aligned}
& \operatorname{Prob}\left(Y \geq y_{k} \mid X\right)=\left\{\begin{array}{l}
\Phi\left(\frac{\beta_{0}}{\sigma_{0}}-\frac{y_{k}}{\sigma_{0}}\right) \text { if } X=0 \\
\Phi\left(\frac{\beta_{1}}{\sigma_{1}}-\frac{y_{k}}{\sigma_{1}}\right) \text { if } X=1
\end{array}\right. \\
& =\Phi\left[\beta_{0}^{\prime}+X \beta+c_{k}+X\left(\frac{1}{\sigma_{1}}-\frac{1}{\sigma_{0}}\right) y_{k}\right]
\end{aligned}
$$

where $c_{k}=y_{k} / \sigma_{0}, \beta_{j}^{\prime}=\frac{\beta_{j}}{\sigma_{j}}, \beta=\beta_{1}^{\prime}-\beta_{0}^{\prime}$ is the main effect of education, and $\left(\frac{1}{\sigma_{1}}-\frac{1}{\sigma_{0}}\right)$ is the coefficient on the interaction between $X$ and $y_{k}$. In other words, introducing heteroskedasticity leads to a specification where the effect of education varies in a smooth (linear) way over the wage distribution. $^{5}$

The heteroskedastic model provides a middle ground between distribution regressions where $\beta_{k}$ vary in a completely unrestricted way and a rank regression model where $\beta_{k}$ is constrained to be the same (except for the intercept) at each cutoff point $y_{k}$. While we use linear interactions in the empirical applications presented here, a more flexible set of interactions between $X$ and polynomial functions in $y_{k}$ can be used.

\subsection{Empirical implementation}

We empirically implement the distribution regression model by dividing the log wage distribution into 58 intervals of width $0.05 \log$ points. ${ }^{6}$ As we are constraining the coefficients to change smoothly across wage cutoffs, the model is estimated by jointly fitting 57 "stacked" probit regressions. ${ }^{7}$ The covariates $\left(Z_{i s t}\right)$ include a set of state $\left(\theta_{s}\right)$, year $\left(\gamma_{t}\right)$, and quarter $\left(\eta_{q}\right)$ fixed effects, as well as state-

\footnotetext{
${ }^{5}$ An alternative interpretation is that the cutoff points in the ordered probit model are now $c_{k}+X\left(\frac{1}{\sigma_{1}}-\frac{1}{\sigma_{0}}\right) y_{k}$, and depend on the value of the covariate $X$.

${ }^{6}$ For over $99 \%$ of observations from 1979 to 2017 , the log wage falls in the range going from $1.6(\$ 4.95)$ to $4.4(\$ 81.50)$. All wages are converted into 2017 dollars. There are 56 intervals of width 0.05 going from 1.6 to 4.4 , plus two intervals for $\log$ wages below 1.6 or above 4.4. While a finer grid could be used in the estimation, doing so would increase the computational burden with limited gains in fitting detailed distributional features. The issue is that most of the wage variation within narrow wage bins is dominated by idiosyncratic variation linked to how wages are reported in the CPS data (e.g., rounding off at 10 cents, 25 cents, or dollar values of nominal wages).

${ }^{7}$ As with an ordered probit model, this estimator is equivalent to a stacked probit model, where the right-hand-side variables are repeated $K$ times and paired with an indicator variable, $\mathbb{I}\left[y_{i t s}>y_{k}\right], k=1, \cdots K$.
} 
specific trends $\left(t \cdot \pi_{s}\right)$ and a rich set of individual characteristics $\left(X_{i s t}\right)$ similar to those used by DFL. These covariates include years of education, a quartic in potential experience, experience-education interactions (16 categories plus experience times education), 11 industry categories 4 occupation categories, and dummy variables for race, marital status, public sector, part-time, and SMSA ${ }^{8}$ These variables are included in the probit models as:

$$
Z_{i s t} \beta=X_{i s t} \beta_{x}+\theta_{s}+\gamma_{t}+\eta_{q}+t \cdot \pi_{s}
$$

In light of the above discussion, we also include interactions $y_{k} Z_{i s t} \lambda$ between the covariates and the cutoff points $y_{k} \cdot{ }^{9}$

We model how the minimum wage $m w$ distorts the wage distribution by creating a large spike at $m w$ and changing the wage distribution above and below the minimum, using event-study type parameters $\varphi_{m}, m \in\left\{-M_{1}, \ldots, M_{2}\right\}$ in the wage space. The parameter $\varphi_{0}$ captures the magnitude of the spike "right at" $m w$. The parameters $\varphi_{m}$ for $m>0$ are used to model spillover effects, while $\varphi_{m}$ for $m<0$ capture the decline in the wage density below the minimum wage. Although these minimum wage parameters' role is intuitively simple, the implementation in a distributional regression model is complicated because we consider minimum wage effects on the cumulative distribution.

For illustration, consider a simple case where spillover effects are limited to one wage bin above the minimum wage, $m \in\{0,1\}$, and where we ignore covariates. The probability that $Y \geq y_{k}$ in absence of the minimum wage is $\operatorname{Prob}\left(Y \geq y_{k}\right)=\Phi\left(\beta_{0}-c_{k}\right)$. Introducing a minimum wage does not change these probabilities in the upper part of the wage distribution above the range of spillover effects. As the minimum wage gets closer to the wage cutoff $y_{k}, \operatorname{Prob}\left(Y \geq y_{k}\right)$ increases due to spillover effects even if the minimum wage is still below $y_{k}$. Prob $\left(Y \geq y_{k}\right)$ increases even more when the minimum wage crosses above $y_{k}$ since, in that case, $\operatorname{Prob}\left(Y \geq y_{k}\right)$ includes the probability of being at the mass point exactly at $m w$.

Using the parameters $\varphi_{0}$ and $\varphi_{1}$, we can write the probabilities in these three cases -- $m w$ much below, a bit below, and just above $y_{k^{--}}$as follows:

\footnotetext{
${ }^{8}$ In models including state-industry union coverage rate, we include industry-specific trends and an interaction between industry and the linear wage cut-off term.

${ }^{9}$ Note that not all covariates are interacted with the linear wage cut-off term. For computational reasons, we restrict the set of interactions to the state and year effects, as well as the experience-interaction dummies.
} 


$$
\operatorname{Prob}\left(Y \geq y_{k}\right)=\left\{\begin{aligned}
\Phi\left(\beta_{0}-c_{k}\right) & \text { if } m w<y_{k-1} \\
\Phi\left(\beta_{0}-c_{k}+\varphi_{1}\right) & \text { if } y_{k-1} \leq m w<y_{k} \\
\Phi\left(\beta_{0}-c_{k}+\varphi_{0}+\varphi_{1}\right) & \text { if } y_{k} \leq m w<y_{k+1}
\end{aligned}\right.
$$

Using equation (3) to compute the probability of being in the wage bin just above the minimum wage, we have:

$$
\operatorname{Prob}\left(y_{k} \leq Y<y_{k+1}\right)=\Phi\left(\beta_{0}-c_{k}+\varphi_{1}\right)-\Phi\left(\beta_{0}-c_{k+1}\right) \text { if } y_{k-1} \leq m w<y_{k} .
$$

Increasing the value of $\varphi_{1}$ increases $\Phi\left(\beta_{0}-c_{k}+\varphi_{1}\right)$ and the probability mass linked to spillover effects in the wage bin just above the minimum wage. Likewise, the probability of being in the wage bin "right at" the minimum wage depends on the parameter $\varphi_{0}$ since:

$$
\operatorname{Prob}\left(y_{k} \leq Y<y_{k+1}\right)=\Phi\left(\beta_{0}-c_{k}+\varphi_{0}+\varphi_{1}\right)-\Phi\left(\beta_{0}-c_{k+1}+\varphi_{1}\right) \text { if } y_{k} \leq m w<y_{k+1} \text {. }
$$

More generally, these minimum wage effects can be captured using a set of dummy variables, $D_{k s t}^{m}$, and writing: $\operatorname{Prob}\left(Y_{i s t} \geq y_{k}\right)=\Phi\left(\beta_{0}+\sum_{m} D_{k s t}^{m} \varphi_{m}-c_{k}\right)$, where $D_{k s t}^{m}=\mathbb{1}\left[y_{k-m} \leq\right.$ $\left.m w_{s t}\right], \quad m \in\left\{-M_{1}, \ldots, M_{2}\right\} .{ }^{10}$ In practice, we allow for up to six spillover effect parameters, and use three parameters to model how the minimum wage reduces the probability distribution below minimum: $m \in\{-3,6\}$.

This method is reminiscent of the bunching/event study design of Cengiz et al. (2019), who estimate changes in the fraction of observations in different dollar wage bins following increases in the minimum wage. Our parameters $\varphi_{m}$ implicitly capture the same type of changes along the wage distribution, but are imbedded in the overall estimation of the wage distribution in the presence of covariates.

We also include another set of dummy variables to account for the substantial heaping at integer values of hourly wages in the CPS data, especially at $\$ 5$ and $\$ 10$ (see Appendix Figure A1). Heaping can have an important impact on estimated probabilities depending on whether a given cutoff point $y_{k}$ is just below or above an integer value. It can also affect the estimated effect of the minimum wage if workers earning the minimum wage round off their wage report to the nearest integer. This measurement error could create spurious spillover effects when the minimum wage is slightly below an integer value. ${ }^{11}$ This is a critical issue in the literature as Autor, Manning, and Smith (2016) present

\footnotetext{
${ }^{10}$ This general model allows for spillover effects higher up in the distribution (e.g. $D_{k s t}^{2} \varphi_{2}$ for two wage bins above the minimum wage), and for negative effects to the part of the distribution below the minimum wage (e.g. $D_{k s t}^{-1} \varphi_{-1}$ ).

${ }^{11}$ For instance, if workers earning a $\$ 9.80$ minimum wage report a $\$ 10$ wage in the CPS, this will increase the mass just above the minimum wage and give a false impression about the importance of spillover effects.
} 
calculations suggesting that minimum wage spillovers effects may be a spurious consequence of measurement error.

Since we are working with $\log$ real wages $Y_{i s t}$, nominal wages in levels, $W_{i s t}$, can be written as $W_{i s t}=P_{t} \cdot \exp \left(Y_{i s t}\right)$, where $P_{t}$ is the price level in year $t$ relative to the base (year 2017 in the empirical analysis). Likewise, the wage cutoffs can be written in nominal terms as $w_{k t}=P_{t} \cdot \exp \left(y_{k}\right)$. We want the interval probability, $\operatorname{Prob}\left(y_{k} \leq Y_{i s t}<y_{k+1}\right)=\operatorname{Prob}\left(w_{k t} \leq W_{i s t}<w_{k+1, t}\right)$, to be larger when, for example, $\$ 10$ is included in the $\left[w_{k t}, w_{k+1, t}\right]$ interval. In this case, the increased probability can be modeled using a dummy variable $L_{k s t}^{10}=\mathbb{1}\left[w_{k, t} \leq 10\right]$ and the corresponding parameter $\gamma_{10}$, so that $\operatorname{Prob}\left(Y_{i s t} \geq y_{k}\right)=\Phi\left(\beta_{0}+L_{k s t}^{10} \gamma_{10}-c_{k}\right) .{ }^{12}$ It follows that $\operatorname{Prob}\left(w_{k t} \leq W_{i s t}<w_{k+1, t}\right)=$ $\Phi\left(\beta_{0}-c_{k}+\gamma_{10}\right)-\Phi\left(\beta_{0}-c_{k+1}\right)$, where the parameter $\gamma_{10}$ determines how much extra mass there is in the wage bin containing $\$ 10$.

As wage heaping is most pronounced for values of wages up to $\$ 10$, we create dummies for heaping at $\$ 5, \$ 10$, and any other integer value up to $\$ 10$. These dummies, $L_{k s t}^{p}$, are included as additional covariates in all estimated models. The resulting probit models being estimated for $k=$ $1, \ldots, 57$ are:

$$
\operatorname{Prob}\left(Y_{i s t} \geq y_{k}\right)=\Phi\left(Z_{i s t} \beta+y_{k} Z_{i s t} \lambda+\sum_{m=-3}^{6} D_{k s t}^{m} \varphi_{m}+\sum_{p=1}^{10} L_{k s t}^{p} \gamma_{p}-c_{k}\right),
$$

Note that the model nests the case of no spillover effects $\left(\varphi_{m}=0\right.$ for $\left.m>1\right)$ considered by DFL. Standard errors are clustered at the state level to allow for correlation across the 57 probit models and for autocorrelation over time.

\subsection{Identification:}

As mentioned earlier, the distribution regression model is identified regardless of whether the prevailing minimum wage is set at the federal or state level. This may be surprising at first glance since the model in equation (4) includes a full set of state and time dummies, where the latter would absorb all the variation in the federal minimum wage in a traditional difference-in-differences setting. As it

\footnotetext{
${ }^{12}$ To use a concrete example, consider the case where two successive cutoff points $w_{k t}$ and $w_{k+1, t}$ are just below and above $\$ 10$ (for example, $\$ 9.75$ and $\$ 10.25)$. The dummy variable $L_{k s t}^{10}$ is equal to 1 at $w_{k t}\left(L_{k s t}^{10}=\mathbb{1}\left[w_{k, t} \leq 10\right]=\right.$ $\mathbb{1}[9.75 \leq 10]=1)$ but turns to 1 at $w_{k+1, t}\left(L_{k+1, s t}^{10}=\mathbb{1}\left[w_{k+1, t} \leq 10\right]=\mathbb{1}[10.25 \leq 10]=0\right)$.
} 
turns out, only allowing for a smooth change in the probit coefficient across wage cutoffs plays an essential role in the identification when the minimum wage only varies at the federal level.

To see this, note that allowing for an unrestricted set of time effects $\gamma_{t}^{k}$ for each cutoff point $y_{k}$ would make it impossible to identify the federal minimum wage's distributional effect. Such an approach would be overly flexible in light of the above discussion on the economic interpretation of the coefficients in the distribution regression. Going back to the example in equation (2), if $X$ was a time instead of an education dummy, the main effect $\beta$ would capture a shift in mean wages over time, while the coefficient $\left(\frac{1}{\sigma_{1}}-\frac{1}{\sigma_{0}}\right)$ on the interaction between $X$ and $y_{k}$ would capture changes in the variance over time. One could also go further by including interaction terms between $X$ and polynomial functions of $y_{k}$ that would capture changes in moments of the wage distribution besides the mean and the variance. The implication remains that time effects should only vary smoothly across the various cut points $y_{k}$ of the distribution.

Identification of minimum wage effects is now possible as the minimum wage "bites" at different points of the distribution at different times, a feature of the wage distribution that cannot be captured by smoothly varying time effects. Intuitively, the minimum wage creates a sharp discontinuity in the probability of being just above and just below its value. As in Doyle (2006) and Jales (2018), identification can be achieved as in a regression discontinuity design provided that the underlying latent wage distribution is smooth around the value of the minimum wage. Constraining the distribution regression's coefficients to change smoothly across the various cut points $y_{k}$ implies that the latent distribution is also smooth. ${ }^{13} \mathrm{We}$ further discuss these identification issues using a series of graphs in Appendix B.

\section{Union threat effects}

In an earlier version of the paper (Fortin, Lemieux, and Lloyd, 2019), we used several strategies to assess the importance of union threat effects. One approach considered was an event-study design focusing on RTW laws introduced in three relatively large Midwestern states, Indiana, Michigan, and

\footnotetext{
${ }^{13}$ As in Fortin and Lemieux (1998), the underlying latent wage distribution is quite flexible despite the normality assumption used to estimate the probit models. The source of additional flexibility is the $g(\cdot)$ function in Fortin and Lemieux (1998); here, it is implemented empirically by estimating a separate coefficient $c_{k}$ at each cutoff.
} 
Wisconsin, in 2011, 2013, and 2015, respectively. ${ }^{14}$ This event-study found evidence of a decline in union coverage and wages in the non-union sector. However, it yielded imprecise estimates, which made it challenging to compute the contribution of threat effects to changes in wage inequality. ${ }^{15}$ As a second alternative strategy, we used the success rate of union organizing elections as a measure of the threat effect. Unfortunately, information about industry is unavailable in recent elections. Furthermore, results based on union elections were fairly similar to those obtained when measuring the threat effect using the unionization rate at the industry-state level. Thus, we follow the latter approach here, and estimate threat effects by adding the unionization rate at the state-industry-year level to the distribution regressions.

Older studies based on cross-sectional data or short repeated cross-sections have generally found that the unionization rate was positively correlated with non-union workers' wages. ${ }^{16} \mathrm{We}$ generalize this approach by looking at how $U_{j s t}$, the rate of unionization in industry $j$ and state $s$ at time $t$, affects the whole distribution of wages. This is achieved by estimating separate distribution regressions for union and non-union workers, and allowing threat effects to vary at different points of the distribution by interacting $U_{j s t}$ with a quartic function in the wage cutoff points $y_{k}$. The resulting probit model being estimated separately for union and non-union workers are:

$$
\operatorname{Prob}\left(Y_{i s t} \geq y_{k}\right)=\Phi\left(A_{i s t}^{k}+\sum_{q=0}^{4} U_{j s t}^{q} \kappa_{q}+t \cdot \pi_{j}\right)
$$

where $\kappa_{q}$ are the parameters associated to the quartic function in $U_{j s t}$, and $A_{i s t}^{k}=Z_{\text {ist }} \beta+y_{k} Z_{i s t} \lambda+$ $\sum_{m=-3}^{6} D_{k s t}^{m} \varphi_{m}+\sum_{p=1}^{10} L_{k s t}^{p} \gamma_{p}-c_{k}$ is the set of other covariates defined in equation (4).

In addition to the state effects, state trends, industry effects, and time effects included in $Z_{i s t} \beta$, we also control for industry trends $\left(t \cdot \pi_{j}\right)$ in equation (5). These covariates are included to control for common shocks that may be correlated with wages and the rate of unionization at the state or industry level. For instance, states with more profitable ("high rent") industries may pay higher wages and have

\footnotetext{
${ }^{14}$ Right-to-work laws typically prohibit union security agreements, or agreements between labor unions and employers, that govern the extent to which an established union can require employees' membership, payment of union dues, or fees as a condition of employment, either before or after hiring.

${ }^{15}$ A difficulty with an event-study of RTW is that often it takes several years for the law to have a full impact as provisions only start binding upon expiration of existing collective bargaining agreements. Biasi and Sarsons (2019) who study the specific case of Wisconsin find that this is indeed the case using data on the expiration dates of public school teachers' collective bargaining agreements.

${ }^{16}$ See, for instance, Freeman and Medoff (1981) and Podgursky (1986). A similar approach has been adopted in recent studies like Rosenfeld et al. (2016) and Denice and Rosenfeld (2018) that use data for a much longer time horizon.
} 
higher unionization rates. After controlling for state and industry effects and trends, the primary source of identifying information left is state-industry specific trends in unionization rates and wages.

For example, consider the case of two industries (manufacturing and services) in two states (Michigan and South Carolina). Including state and industry trends and fixed effects controls for the fact that, for instance, wages and unionization rates may be declining faster in Michigan than in South Carolina because of adverse shocks in the manufacturing sector that account for a larger share of employment in Michigan. Thus, our empirical strategy leverages variation linked to the faster relative decline in unionization in Michigan's manufacturing sector relative to South Carolina. We then look at whether this faster decline in the unionization rate is linked to a faster decline in non-union (or union) workers' wages in the Michigan manufacturing sector.

Figure 2 illustrates these trends by Census Bureau Region and high- vs. low-unionization industries. Panel A shows that, in some industries (e.g., services and trade), the unionization rate is uniformly low across all regions. By contrast, there is much more regional (state) variation among high-unionization rate industries, shown in Panel B, like manufacturing, construction, transportation, education, and public administration. Notably, unionization rates have fallen fastest among high unionization industries in the Midwest relative to other regions.

Of course, there are possibly state-industry specific shocks that affect both wages and unionization rates. However, there is no particular reason to believe the impact of these shocks would follow the pattern expected from union wage compression effects. For example, Chetverikov, Larsen, and Palmer (2016) extend the Autor, Dorn, Hanson (2013) analysis of the "China shock" to quantiles of the wage distribution. They found that among men, the wage impacts of commuting zone-level trade exposure are uniform across most of the distribution, whereas among women, these wages impacts are monotonically increasing. ${ }^{17}$ By contrast, the union wage effects literature (e.g., Card, 1996, and Firpo, Fortin, and Lemieux, 2009) indicates that unions have a relatively larger impact on workers' wages in the middle (or bottom) of the distribution, but little or even a negative impact on workers at the top of the distribution. Based on this evidence, it is natural to expect that union threat effects should be much more significant in the middle or bottom of the distribution than at the top. Finding such a pattern

\footnotetext{
${ }^{17}$ Figure 2 of Chetverikov, Larsen, and Palmer (2016) shows that the point estimates of negative effects of the shock are larger than OLS estimates in the three bottom vingtiles and smaller in the four upper vingtiles of the female wage distribution. Figure 3 shows that negative effects larger than OLS estimates for male workers are found only in the three bottom vingtiles. However, in neither case are these differences statistically significant.
} 
would be more supportive of a story based on unions' threat effects than on unmodelled state-industry shocks.

An additional way of probing the validity of the results is to examine whether the rate of unionization in other industries in the same state affects the wage distribution. For example, suppose the unionization rate declines in the construction sector but remains constant in manufacturing. In that case, we should not observe a decline in non-union manufacturing wages manufacturing in response to declining threat effects (a lower unionization rate) in the construction sector. Looking at the impact of changing unionization in other sectors can be viewed as a falsification test of our central hypothesis that threat effects are captured by unionization at the narrower state and industry level. ${ }^{18}$ We explore these issues in Section 4.4 by including both the unionization rate in narrower and broader sets of industries.

\section{Data and estimation results}

\subsection{Data}

Data from the 1979-2017 MORG CPS are used to estimate the distribution regressions. The sample selection criteria and variable definitions are similar to those used in DFL. Note that the union status of workers is only available from 1983 on. As in DFL, we use union status information from the 1979 May CPS matched with the May-August MORG to extend the analysis back to 1979. One difference relative to DFL is that we impute top-coded wages using a stochastic Pareto distribution (see Firpo, Fortin, and Lemieux, 2018). This imputation helps obtain a smoother wage density at the upper end of the distribution. In the case of workers paid by the hour, our wage measure is the hourly wage directly reported by the worker. The wage measure is average hourly earnings (usual earnings divided by usual hours of work) for workers not paid by the hour. Wages are deflated into constant dollars of 2017 using the CPI-U. See Lemieux (2006) for more information about data processing.

We use union coverage as our measure of unionization throughout. We focus only on observations with unallocated wages to avoid the large attenuation bias linked to the fact union status

\footnotetext{
${ }^{18}$ An alternative explanation could be that in economically close sectors - in the sense that workers often move between these sectors - the threat of unionization may also depend on what happens in these related sectors. But even in these circumstances, we should expect the unionization rate in these related industries to have a smaller impact on wages than the unionization rate in the industry where the worker is employed. By contrast, if unionization rates in other sectors capture spurious shocks hitting a local area, unionization rates in other sectors should be strongly correlated with wages, suggesting that our research design is invalid.
} 
is omitted in the CPS wage imputation (Hirsch and Schumacher, 2003). The value of the minimum wage used in the estimation is the maximum of the federal and state minimum computed at the quarterly level.

Summary statistics are reported in Table 1. These statistics, as well as distribution regression models, are all weighted using CPS sample weights. As is well known, measures of overall inequality (the 90-10 gap, the standard deviation of log wages, and the Gini coefficient) and top-end inequality (the 90-50 gap) increase steadily over time. By contrast, low-end inequality (50-10) only increases between 1979 and 1988 when the minimum wage's real value was rapidly declining. Table 1 also shows that the rate of unionization declined much faster for men than women, and that the four years used to divide the sample $(1979,1988,2000$, and 2017) were at similar points in the economic cycle (comparable unemployment rates, especially for men).

\subsection{Minimum wage effects}

We separately estimate the distribution regression models for men and women over the 1979-88, 19882000, and 2000-17 periods. After some experimentation, we settled on specifications that allow for spillover effects up to $30 \log$ points above the minimum wage in 1979-88 and $20 \log$ points above the minimum wage in subsequent periods. ${ }^{19}$ Besides the minimum wage variables, other variables included in the models consist of state and year effects, state-specific trends, and the other covariates mentioned when discussing the model in equation (4).

Table 2 reports the estimated coefficients for the set of minimum wage dummies $\left(\varphi_{m}\right)$ and heaping dummies corresponding to integer values of nominal wages $\left(\gamma_{p}\right)$ for each of the six specifications (men and women for three time periods). The estimated coefficients for the other covariates are not reported for the sake of brevity, and standard errors are clustered at the state level. The estimated coefficient for being "right at" the minimum wage, $\varphi_{0}$, is large and significant in all specifications, though it tends to decline over time. The coefficients capturing spillover effects, $\varphi_{m}$ for $m>0$, are also precisely estimated and tend to decline as we move further away from the minimum wage.

Interestingly, the coefficients associated with being below the minimum wage, $\varphi_{m}$ for $m<0$, tend to be small and often insignificant. This finding does not imply that the minimum wage does not

\footnotetext{
${ }^{19}$ Spillover effects above these levels were not found to be statistically significant.
} 
reduce the wage density below the minimum. Since we are working with cumulative probabilities, a large value of the "spike" parameter $\varphi_{0}$ means that $\operatorname{Prob}\left(Y_{i s t} \geq y_{k}\right)$ is much lower for all wage cutoffs $y_{k}$ that are below the value of the minimum wage. Finding small values of $\varphi_{m}$ for $m<0$ means we do not need a sizable additional reduction in probabilities to fit the data. ${ }^{20}$ The heaping parameters are statistically significant and substantially improve the fit of the model, consistent with the descriptive evidence reported in Appendix Figure A1. ${ }^{21}$

There is also clear evidence that minimum wage effects are substantially larger in 1979-88 than in subsequent years. Unlike Lee (1999) and Autor, Manning, and Smith (2016), who use different estimation methods for different years, our method yields estimates based on the same method but for different years. The results suggest that Autor, Manning, and Smith (2016)'s conclusion that Lee overstated the importance of spillover effects is at least partly due to the fact their estimates are based on more recent data.

As it is challenging to interpret the magnitude of coefficients estimated using probit models, we transform the results into marginal effects that are reported in Figure 3. The marginal effects are computed as the difference between the predicted probabilities with and without a minimum wage. The counterfactual probabilities without a minimum wage are obtained by setting the minimum wage coefficients, $\varphi_{m}, m \in\{-3,6\}$, to zero in equation (4) and using the estimated value of the other parameters to compute:

$$
\widehat{\mathrm{P}}_{i s t}^{k, c}=\Phi\left(Z_{i s t} \hat{\beta}+y_{k} Z_{i s t} \hat{\lambda}+\sum_{p=1}^{10} L_{k s t}^{p} \hat{\gamma}_{p}-\hat{c}_{k}\right)
$$

While we could compare this counterfactual distribution to the observed wage distribution, doing so would mix the impact of different values of the minimum wage, depending on state and year. Instead, we compute the predicted wage distribution for the median minimum wage in the relevant analysis period. The predicted wage distribution with a minimum wage is, therefore, calculated as:

\footnotetext{
${ }^{20}$ In the example used in equation (3), the probability when the wage cutoff is one wage bin below the minimum wage is $\operatorname{Prob}\left(Y_{i s t} \geq y_{k}\right)=\Phi\left(\beta_{0}-c_{k}+\varphi_{-1}+\varphi_{0}+\varphi_{1}\right)$. Compared to a case without a minimum wage where $\operatorname{Prob}\left(Y_{\text {ist }} \geq y_{k}\right)=$ $\Phi\left(\beta_{0}-c_{k}\right)$, the probability is much larger and the complementary probability $\operatorname{Prob}\left(Y_{i s t}<y_{k}\right)$ much smaller when $\varphi_{0}+$ $\varphi_{1}$ is large, regardless of the value of $\varphi_{-1}$. Thus, the role of $\varphi_{-1}$ is to "fine-tune" the features of the wage distribution below the minimum wage, as opposed to making sure only a few workers are observed there.

${ }^{21}$ To reduce the number of parameters linked to heaping at integer values of nominal wages, we constrain the parameters for $\$ 1$ to $\$ 10$ to be the same except for $\$ 5$ in $1979-88$, and $\$ 10$ later on, that are allowed to exhibit a larger spike.
} 


$$
\widehat{\mathrm{P}}_{i s t}^{k}=\Phi\left(Z_{i s t} \hat{\beta}+y_{k} Z_{i s t} \hat{\lambda}+\sum_{m=-3}^{6} D_{k, m e d}^{m} \hat{\varphi}_{m}+\sum_{p=1}^{10} L_{k s t}^{p} \hat{\gamma}_{p}-\hat{c}_{k}\right),
$$

where the minimum wage dummies $D_{k s t}^{m}$ in equation (4) have been replaced by the dummies $D_{k, m e d}^{m}$ corresponding to the median minimum wage.

Since distribution regressions yield estimates of cumulative probabilities, the estimated probability of log wages $Y_{i s t}$ lying in a given interval $\left[y_{k}, y_{k+1}\right]$ is the difference between the predicted cumulative probabilities $\widehat{\mathrm{P}}_{i s t}^{k}$ and $\widehat{\mathrm{P}}_{i s t}^{k+1}$. Call this difference $\widehat{Q}_{i s t}^{k}=\widehat{\mathrm{P}}_{i s t}^{k}-\widehat{\mathrm{P}}_{i s t}^{k+1}$. Averaging out these individual probabilities over the entire sample yields the unconditional probability $\hat{Q}_{t}^{k}$, where $\hat{Q}_{t}^{k}=$ $\frac{1}{N_{t}} \sum_{i} \hat{Q}_{i s t}^{k}$. The marginal effects are obtained by comparing $\hat{Q}_{t}^{k}$ to the counterfactual value $\hat{Q}_{t}^{k, c}$ that would prevail in absence of the minimum wage. ${ }^{22}$ For clarity, we show the marginal effects, $M E_{t}^{k}$, in percentage terms: $M E_{t}^{k}=100 \cdot\left(\hat{Q}_{t}^{k, c}-\hat{Q}_{t}^{k}\right) / \hat{Q}_{t}^{k}$.

Figure 3 shows that the marginal effects corresponding to the minimum wage spike are quite large. Depending on year and gender, the probability of being "right at" the minimum wage increases by 150 to $300 \%$. Spillover effects in the first interval to the right of the minimum wage are also quite large, but decline as we move further above the minimum. Visually speaking, Figure 3 shows that spillover effects are substantially more important in 1979-88 than in subsequent periods. The same minimum wage coefficient, $\varphi_{m}$, will have a larger effect on probabilities when the minimum wage bites more, i.e., when it is relatively higher up in the distribution. This higher relative position explains in part why, for instance, the marginal effects are larger for women than men in 1979-88. ${ }^{23}$ That said, the decline in marginal effects may not solely reflect a decline in the "bite" in the minimum wage since the estimated coefficients reported in Table 2 are declining too.

To further explore these issues, we use our estimates to assess how much of the decline in the marginal effects over time reflect a change in how the minimum wage is reshaping the wage distribution instead of a declining "bite" in the minimum wage. We do so using a simple measurement model. First, consider the "fraction affected" $F A_{t}$, which represents the fraction of workers who would be below the minimum wage $m w_{t}$ in absence of a minimum wage (we ignore state variation in the

${ }^{22} \hat{Q}_{i s t}^{k, c}=\widehat{\mathrm{P}}_{i s t}^{k, c}-\widehat{\mathrm{P}}_{i s t}^{k+1, c}$ and $\hat{Q}_{t}^{k, c}$ is defined as $\hat{Q}_{t}^{k, c}=\frac{1}{N_{t}} \sum_{i} \hat{Q}_{i s t}^{k, c}$.

${ }^{23}$ For example, the coefficient for the "at the minimum wage" dummy is $13 \%$ larger for women than men in 1979-88 ( 0.557 vs. 0.494 in Table 2), while the corresponding marginal effect is $27 \%$ larger ( $277 \%$ vs. $218 \%$ in Figure $3 a)$. 
minimum wage to simplify the exposition). The fraction $F A_{t}$ can be computed by summing up the predicted probabilities $\widehat{\mathrm{Q}}_{t}^{k, c}$ over the wage bins that are below $m w_{t}$.

Using the terminology of Cenzig et al. (2019), we can think of the minimum wage as creating some "missing" mass below the minimum that gets redistributed as "excess" mass at or above the minimum wage. These effects can be captured using the following three parameters: $\delta_{1, t}$, the fraction of affected observations $\left(F A_{t}\right)$ that move up to exactly the minimum wage; $\delta_{2, t}$, the fraction of affected observations that move above the minimum wage and contribute to spillover effects; and $\delta_{0, t}=1-\delta_{1, t}-\delta_{2, t}$, the fraction of observations that remain below the minimum wage due to imperfect compliance, measurement error, or subminimum wage (e.g., for tip workers). In this setting, the missing mass is given by $\left(1-\delta_{0, t}\right) \cdot F A_{t}$.

To illustrate how to compute these "mass changing" parameters, consider the estimated wage distributions for 1979-88 with and without the minimum wage. The two distributions are reported in Appendix Figure A2, Panel A, where we plot the values of $\widehat{\mathrm{Q}}_{t}^{k}$ and $\widehat{\mathrm{Q}}_{t}^{k, c}$ recentered around the median value of the minimum wage. The fraction affected $F A_{t}$ is the sum of the bars below the minimum wage for the counterfactual distribution that would prevail in absence of a minimum wage. ${ }^{24}$ The difference between the cumulative sum of the bars for the two distributions below the minimum wage corresponds to the "missing mass" in Cenzig et al. (2019).

The fraction of affected observations redistributed at the minimum wage is the difference between the two bars at the minimum wage bin: $\delta_{1, t}=\left(\widehat{\mathrm{Q}}_{t}^{k_{0}}-\widehat{\mathrm{Q}}_{t}^{k_{0}, c}\right) / F A_{t}$. Likewise, the fraction of affected observations that gets redistributed above the minimum wage is:

$$
\delta_{2, t}=\sum_{k=k_{0}+1}^{k_{0}+6}\left(\widehat{\mathrm{Q}}_{t}^{k}-\widehat{\mathrm{Q}}_{t}^{k, c}\right) / F A_{t}
$$

where $k_{0}$ indicates the wage bin where the minimum wage lies $\left(y_{k_{0}} \leq m w_{t} \leq y_{k_{0}+1}\right)$.

The results of this exercise are reported in the first panel of Table 3. As expected, the bite of the minimum wage, as summarized by $F A_{t}$, is larger for women and declines over time. Interestingly, the fraction of affected workers who are pushed up to the minimum wage, $\delta_{1, t}$, ranges from 0.30 to 0.34 , and is remarkably stable across time and gender. Thus, differences in marginal effects reported in Figure 3 reflect differences in the fraction of affected workers, as opposed to the fraction of affected workers who are pushed up to the minimum wage.

\footnotetext{
${ }^{24}$ The figures only show the distribution up to $30 \log$ points below the minimum, but lower wage values are also used to compute $F A_{t}$.
} 
By contrast, the fraction of observations $\left(\delta_{2, t}\right)$ that are pushed up above the minimum wage declines over time, going from 0.37 in 1979-88 to 0.26 in 2000-17 for women, and from 0.37 to 0.20 for men. Thus, the decline in marginal effects associated with spillover effects reflects a combination of how many workers are affected, and how the minimum wage transforms the distribution. Since $\delta_{2, t}$ declines while $\delta_{1, t}$ remains stable over time, the fraction of affected workers remaining below the minimum, $\delta_{0, t}$, needs to increase since $\delta_{0, t}=1-\delta_{1, t}-\delta_{2, t}$. One possible explanation for this finding is that a substantial share of wages observed below the minimum wage is due to measurement error. This share may have grown over time as the minimum wage has moved further down in the left tail of the wage distribution where measurement error accounts for a large share of the wage density. We explore these issues in more detail in Section 4.3.

In this simple measurement model, we implicitly assume that while some affected workers are pushed above the minimum, the wages of "unaffected workers" -those already earning at least the minimum wage - are unchanged. This assumption is unrealistic, as these workers' wages would likely go up due to the presence of spillover effects. We allow for this possibility by considering an alternative model where wage ranks are preserved when the minimum wage is introduced. In practice, this means that the wage bin where the minimum wage lies should first be filled by "affected workers". Workers who were in the minimum wage bin before the increase are pushed above the minimum as this bin gets filled by workers from lower down in the distribution. We define the fraction of these workers being pushed up as $\delta_{3, t}$.

Not surprisingly, the results reported for this "rank preservation" model in Panel B of Table 3 indicate that a higher fraction of affected workers is now pushed to the minimum wage bin. We also find that, in most cases, all workers previously in the minimum wage bin are now pushed above the minimum wage $\left(\delta_{3, t}\right)$. Although the mechanisms underlying these spillover effects are different from those discussed earlier, our main conclusions about why spillover effects have declined over time remain. Spillover effects get smaller over time due to a decline in the fraction of workers affected and changes in the way the minimum wage shifts the distribution, as summarized by the $\delta$ parameters.

\subsection{Are spillover effects real or just due to measurement error?}

Measurement error is another reason why Autor, Manning, and Smith (2016) argue that Lee (1999) may have overstated the contribution of minimum wage spillover effects on inequality growth. Measurement error may indeed result in spurious spillover effects if a fraction $p$ of workers paid 
exactly the minimum wage misreport their wages, and if measurement error follows a continuous zero mean distribution (e.g., a normal distribution with mean 0 and variance $\sigma^{2}$ ). When the actual minimum wage spike is large, and many workers misreport their wages (i.e., $p$ is large), we may expect to see an abnormal concentration of observations just above and below the minimum wage. These spurious spillover effects potentially overstate the equalizing effects on the minimum wage on the wage distribution.

We use two approaches to address this important concern. We first note that not all forms of measurement error necessarily result in spurious spillover effects. As noted above and illustrated in Appendix Figure A1, there are large spikes in the wage distribution at integer values of wages. While some of these spikes may be real (see Dube, Manning, and Naidu, 2018), many workers likely misreport their wages by rounding them off to the nearest integer. Unlike the type of measurement error discussed above, rounding off at the nearest integer may overstate or understate spillover effects. $^{25}$

Whether or not measurement error linked to rounding off at integer values results in spurious spillover effects is ambiguous, and depends on the distribution of the difference between the minimum wage and the nearest integer. We can empirically evaluate the consequences of this form of measurement error by comparing our estimated spillover effects where we do control for rounding off with the set of dummies $L_{k s t}^{p}$ to what we would find without controlling for these dummies. The results of this comparison for 1979-88 are reported in Appendix Figure A3. We find that the estimated spillover effects are, if anything, smaller when we do not control for the rounding off. Thus, this potentially important form of measurement error is unlikely to generate spurious spillover effects that would overstate the contribution of changes in the minimum wage to the increase in inequality.

Unlike measurement error linked to rounding off at integer values, more standard forms of measurement error like the one discussed above unambiguously overstate the magnitude of spillover effects. To assess the bias's magnitude, we follow Autor, Manning, and Smith (2016), who use the observed wage distribution below the minimum wage to construct bounds for spillover effects. One

\footnotetext{
${ }^{25}$ For example, if the minimum wage is itself an integer value (e.g. \$10), the size of the spike may be overstated, and spillover effects understated, if worker paid a bit above the minimum (e.g. \$10.15) round off their reported wage to the value of the minimum wage. If the minimum wage is a bit above an integer value, the rounding off may increase the false reporting just under the value of the minimum. The case where spillover effects would be overstated is when the minimum wage is a bit below an integer value (e.g., \$9.80), and workers at the minimum falsely report the integer value, leading to spurious extra mass just above the minimum wage.
} 
extreme assumption is that all wages observed below the minimum are due to noisy wage reports by workers earning exactly the minimum wage. Under the additional assumption that measurement error is symmetric, the lower tail of the distribution can be used to adjust the distribution above the minimum wage. The corrected wage distribution is obtained by moving up all the lower part of the distribution to the minimum wage and moving down in a symmetric way the same fraction of observations from the part of the distribution just above the minimum. We also consider an alternative assumption where measurement error only accounts for half of the wage distribution observed below the minimum wage, the remainder being due to non-compliance and subminimum wages. We refer to this case as a "partial" adjustment for measurement error.

Panels B and C of Appendix Figure A2 illustrate the impact of the measurement error correction on the wage distribution for the 1979-88 period. As we only consider measurement error for workers paid the minimum wage, the counterfactual distribution without a minimum wage (red bars in the figures) remains unchanged when the different adjustment factors are applied. ${ }^{26}$ As we move to the partial (50 percent) measurement error adjustment in Panel B and the full adjustment in Panel C, the wage distribution becomes increasingly concentrated right at the minimum wage. By the same token, the density just above and below the minimum wage declines as the measurement error corrections moves some of the density to the spike.

Spillover effects are measured as the difference between the two distributions with and without the minimum wage. Adjusting for measurement error reduces these effects, but they generally remain positive. That said, the figures suggest that even a reasonable amount of measurement error substantially understates the size of the minimum wage spike and overstates the importance of spillover effects. ${ }^{27}$

${ }^{26}$ It is unrealistic to assume that measurement error should affect only those paid the minimum wage rather than all workers. That said, adding measurement error to an otherwise smooth distribution - like the counterfactual distribution without a minimum wage shown in Appendix Figure A3 - should not change the shape of the distribution very much. By contrast, when there is a massive spike at the minimum in the actual wage distribution, adding measurement error may substantially change the distribution's shape by smoothing out the spike. So although our measurement error model is highly simplified, it illustrates the consequences of measurement for estimating the relative size of the minimum wage spike and the spillover effects.

${ }^{27}$ To assess how reasonable the implied measurement error is, consider the case with partial (50 percent) adjustment. In the case of women, we find that 26 percent of minimum wage workers misreport their wages, and that the variance of errors is equal to 0.006 . The variance of measurement error is equal to the product of these two numbers and represent 18 (7) percent of the total variance of log wages in 1979 (1988). The comparable numbers for men are 10 and 7 percent in 1979 and 1988, respectively. These figures are of the same order of magnitude as those found using validation surveys (see, e.g., Bound and Krueger, 1991). 
The impact of the measurement error corrections is summarized in Panels C and D of Table 3 using the partial (50 percent) adjustment for measurement error. As in Appendix Figure A3, adjusting for measurement error increases the fraction $\delta_{1, t}$ of affected workers who are pushed up to the minimum wage. Likewise, the "missing mass" increases as a smaller fraction $\delta_{0, t}$ remains below the minimum wage after controlling for measurement error. Spillover effects, captured by the parameters $\delta_{2, t}$ and $\delta_{2, t}$, also decline. That said, the main finding obtained without correcting for the minimum wage remains. The spillover effects documented in Figure 3 decline over time due to a combination of a smaller bite of the minimum wage, and a change in the way the minimum wage shifts the wage distribution, as summarized by the $\delta$ parameters.

It should also be noted that although spillover effects may partly reflect measurement error, this does not necessarily reduce the minimum wage's overall impact on the wage distribution. Correcting for measurement error also increases the fraction of workers whose wages are moved up from below the minimum to the minimum wage spike, as observed when comparing Panels $\mathrm{C}$ and $\mathrm{D}$ of Table 3 to Panels A and B. This shift increases the equalizing effects of the minimum wage, which compensates for the more modest equalizing effects linked to spillover effects.

\subsection{Distribution regression estimates of the effect of unionization}

Before presenting our main estimates of the effect of the state-industry unionization rate on the wage distribution, we report results from simple OLS regression of the log wage on the unionization rate for union and non-union workers in Table 4. This provides a simple way of summarizing the average union threat effects over the whole distribution and exploring the robustness of the results to alternative definitions of the level at which threat effects operate. In our preferred specification, we use the unionization $U_{j s t}$ at the industry-state level using 11 industry categories. ${ }^{28}$ Using a narrower set of industries would be challenging due to sample sizes. In Table 4, we present the regression models for men and women pooled together to simplify the exposition. All models include the set of covariates mentioned when discussing the distribution regression model of equation (5). Recall that the covariates include a full set of state, industry, quarter and year dummies, as well as state- and industry-specific linear trends.

\footnotetext{
${ }^{28}$ The 11 industries are the primary sector, construction, manufacturing, transportation and utilities, wholesale and retail trade, financial services, business and professional services, health and welfare services, personal services, education services, and public administration.
} 
Looking first at non-union workers in columns (1) to (4), the results indicate that a one percentage point increase in unionization rate at the state-industry level increases wages by 0.11 to 0.15 percent in most specifications. The estimates are essentially unchanged when we also include the state unionization rate in column (2), or a full set of state-year interactions in column (3). Although it is challenging to identify the effect of the state-level unionization rate (the estimates are noisy and unstable) when we include state linear trends, the results suggest that spillover effects mostly take place at the narrower industry level.

A similar conclusion is reached when including the unionization rate at a broader industry level in column (4). The three broad industrial categories considered are i) traditional high-unionization private sector industries (construction, manufacturing, transportation, and utilities), ii) highunionization public sector industries (educational services and public administration), and iii) lowunionization services, as well as primary industries. After controlling for the unionization rate in these broader industries, we only rely on the variation within these broader industries to identify the unionization rate's effects at the narrower industry level. Although the estimates are less precise than in the other columns, the overall magnitude of the effects remains relatively unchanged, ranging from 0.07 in $2000-17$ to 0.18 in 1979-88. By contrast, the unionization rate's effects at the broader industry level are small and not statistically significant. These results provide strong evidence that spillover effects primarily arise at the narrower industry-state level used in the distribution regression estimates, presented below.

Interestingly, the results reported in columns (5) to (8) indicate that union spillover effects are larger for union than non-union workers, i.e., the union wage gap tends to be larger when the unionization rate is higher. For union workers, the estimated spillover effects at the narrower industrystate level are relatively stable across specifications. One exception is the model (column 8) with the unionization rate at the broader industry level in 1988-2000 and 2000-2017, where the two unionization rate variables have comparable effects. We nonetheless conclude that, on balance, most spillover effects appear to be occurring at the narrower industry level, and we focus on this measure of unionization in the remainder of the analysis.

Table 5 reports estimates from the distribution regression models with the state-industry-year rate of unionization added as an explanatory variable. Again, we show results separately for union and non-union workers. As noted above, we model changing impacts over the wage distribution by interacting the unionization rate with a quartic function in $y_{k}$ (normalized to zero at the midpoint of the 
$y_{k}$ range). All models include a set of industry trends in addition to the other explanatory variables listed in Section 3.2. The models are estimated separately for union and non-union workers for two reasons. First, we want to allow for different effects of the unionization rate (and other covariates) for these two groups. Second, and as discussed earlier, estimating separate models for union and nonunion workers is essential for computing standard counterfactual experiments illustrating the contribution of de-unionization to changes in the wage structure. ${ }^{29}$

Panel A of Table 5 reports the estimated effect of the unionization rate for non-union workers. The main effect of the unionization rate is large and statistically significant in all three time periods. The unionization rate's estimated effect is substantially smaller for women, especially in the earlier periods. Panel B shows that the unionization has a larger effect on union workers, suggesting that the union wage gap increases with the unionization rate.

While most of the interactions between the unionization rate and the polynomials in $y_{k}$ are statistically significant, it is difficult to infer the shape of the estimated effects from the results reported in Table 5. To facilitate interpretation, we translate the estimated parameters for non-union workers into wage impacts at different points of the distribution by considering a $1 \%$ increase in the unionization rate. The wage effects are obtained by first comparing the CDF computed from the distribution regressions - using the observed rates of unionization - to the counterfactual CDF that would prevail if the unionization rate was one percentage points higher. The horizontal distance between the two CDFs indicates by how much wages change at each percentile of the distribution under this counterfactual experiment.

The results of this exercise are displayed in Figure 4, panels A and B. The threat of unionization has the largest impact in the lower middle of the distribution and tends to be substantially larger for men than women. The effect is positive over most of the distribution before turning negative around the $80^{\text {th }}$ percentile.

We also report more traditional direct or "shift-share" effects of unionization in Panels C and D. These effects are computed by contrasting the observed wage distribution with the counterfactual distribution that would prevail if the unionization rate was increased by one percentage point. The

${ }^{29}$ Appendix C provides comparable results using the RIF-regression methodology of Firpo, Fortin, and Lemieux (2009). 
counterfactual distribution is computed by reweighting union and non-union observations to increase the conditional probability of unionization by one percentage point. ${ }^{30}$

Interestingly, both shift-share effects and threat effects (for non-union workers) reported in Figure 4 are hump-shaped. The hump-shape feature of the direct (or shift-share) effect is similar to the findings of Firpo, Fortin, and Lemieux (2009) who use RIF-regression to estimate union wage effects (see also Panel A of Appendix Figure C1). Intuitively, the pattern of union wage effects - positive on average but declining in the upper part of the distribution - is consistent with other evidence on the effect of unions on the wage structure. For instance, Card (1996) shows that the union wage premium is positive on average, but declines over the skill distribution.

It is not as intuitive, however, to see why the union effect first grows before reaching a peak around the middle of the distribution. Part of the story is that changes in the rate of unionization have little impact at the bottom of the distribution where wages mostly depend on the minimum wage. Another part of the story is that very few workers are unionized at the bottom of the distribution. The issue is discussed in more detail using an example with uniform distributions presented in Appendix D. Note that the hump-shaped pattern of union effects has important implications on how de-unionization affects the shape of the wage distribution. It implies that unionization substantially reduces the 90-50 gap, but also slightly increases the 50-10 gap. Interestingly, DFL reach a similar conclusion using a reweighting approach, as we do with the distribution regression method (see below).

The similarity in the shape of the threat effects and the traditional shift-share effects is remarkable, given that these effects are computed using very different procedures. The results are consistent with non-union employers trying to emulate the union wage structure in response to the threat of unionization. This supports the view that the effects of the unionization rate at the stateindustry-year-level capture union threat effects, as opposed to un-modelled state-industry shocks that may affect both wages and unionization. It is also re-assuring to note that, using different approaches and data, Farber et al. (2020) also reach the conclusion that unions have both a direct and indirect (threat) effect on wages. Despite the challenges of finding a credible instrument for the rate of unionization, the evidence presented here and in Farber et al. (2020) strongly suggests that the effect of

\footnotetext{
${ }^{30}$ The reweighting factor used in DFL is $\psi(X)=U \frac{\operatorname{Pr}^{c}(U=1 \mid X)}{\operatorname{Pr}(U=1 \mid X)}+(1-U) \frac{\operatorname{Pr}^{c}(U=0 \mid X)}{\operatorname{Pr}(U=0 \mid X)}$ where $U$ is a union status dummy and $X$ are covariates. The counterfactual probability of unionization, $\operatorname{Pr}^{c}(U=1 \mid X)$, used in DFL is based on other years, while we use $\operatorname{Pr}^{c}(U=1 \mid X)=\operatorname{Pr}(U=1 \mid X)+0.01\left(\right.$ and $\left.\operatorname{Pr}^{c}(U=0 \mid X)=\operatorname{Pr}(U=0 \mid X)-0.01\right)$ in the counterfactual experiment considered here.
} 
union on wages goes beyond the direct effect that has been the focus of most of the unions and wage inequality literature.

\section{Decomposition results}

We are now able to estimate how much of the change in the wage distribution over the 1979-2017 period can be accounted for by changes in the minimum wage and the rate of unionization in the presence of spillover effects. In the case of the minimum wage, we first compute counterfactual probabilities by replacing the observed minimum wages in the end period (say 1988) with the minimum wage in the base period (say 1979). For example, for each individual $i$ in year 1988, the predicted cumulative probabilities estimated using the distribution regressions are:

$$
\widehat{\mathrm{P}}_{i s 88}^{k}=\Phi\left(Z_{i s 88} \hat{\beta}+y_{k} Z_{i s 88} \hat{\lambda}+\sum_{m=-3}^{6} D_{k s 88}^{m} \hat{\varphi}_{m}+\sum_{p=1}^{10} L_{k s t}^{p} \hat{\gamma}_{p}-\hat{c}_{k}\right),
$$

while the counterfactual cumulative probabilities are:

$$
\widehat{\mathrm{P}}_{i s 88}^{k, c}=\Phi\left(Z_{i s 88} \hat{\beta}+y_{k} Z_{i s 88} \hat{\lambda}+\sum_{m=-3}^{6} D_{k s 79}^{m} \hat{\varphi}_{m}+\sum_{p=1}^{10} L_{k s t}^{p} \hat{\gamma}_{p}-\hat{c}_{k}\right) .
$$

In Section 4.2 we introduced $\hat{Q}_{i s t}^{k}$, the predicted interval probability that individual $i$ is in a given interval $\left[y_{k}, y_{k+1}\right]$, where $\widehat{Q}_{i s t}^{k}=\widehat{\mathrm{P}}_{i s t}^{k}-\widehat{\mathrm{P}}_{i s t}^{k+1}$. Averaging these probabilities over all individuals in 1988 yields the predicted probability $\hat{Q}_{88}^{k}$, and its counterfactual counterpart $\hat{Q}_{88}^{k, c}$. We can then compute the various counterfactual statistics of interest in 1988 by reweighting observations with a wage in the interval $\left[y_{k}, y_{k+1}\right]$ using the reweighting factor $\hat{\psi}_{88}^{k}=\hat{Q}_{88}^{k, c} / \widehat{Q}_{88}^{k} .{ }^{31}$ We use the same procedure for the periods 1988-2000 and 2000-17.

To isolate the contribution of spillover effects, we use DFL's "tail pasting" procedure where the distribution in the year with a lower minimum wage (say 1988) is replaced by the distribution in the year with a higher minimum wage (say 1979) for wages at or below the higher minimum. The difference between our main estimates (that include spillover effects) and those obtained using this alternative procedure represents the contribution of spillover effects.

In the case of the decline in unionization rate, we also compare the predicted probabilities obtained using observed values of the unionization rates in the end period (say 1988) to the

\footnotetext{
${ }^{31}$ We use this procedure to preserve the observed wage distribution within each wage bin. With very narrow bins we could simply use mid-points to calculate distributional statistics of interest such as the Gini coefficient, the wage density, etc. We instead use slightly wider wage bins to simplify the estimation and perform a bin by bin reweighting to construct a counterfactual distribution that also includes within-bin wage dispersion.
} 
counterfactual probabilities obtained using the base period unionization rate. As such, the procedure is very similar to the one described above for the minimum wage. As in the minimum wage case, and for the sake of comparison with DFL, we first compute the contribution of de-unionization without spillover effects using DFL's reweighting (shift-share) procedure. More specifically, we first reweight data in the end period (say 1988) to have the same distribution of unionization as in the base period conditional on covariates, and then add spillover effects to the reweighted distribution using the procedure we just described.

Figures 5 to 7 report the actual and counterfactual distributions corresponding to the three periods of analysis 1979-1988, 1988-2000, and 2000-2017. In each figure, panel A shows the counterfactual distribution corresponding to a model where the minimum wage is held constant at the base period level, and spillovers are accounted for. Panel B then shows the counterfactual corresponding to the base period's minimum wage and unionization rate, accounting for spillovers in both cases. Thus, a comparison of the two panels highlights the interaction between these two forms of spillovers. The inequality measures corresponding to these distributions can be found in Tables 6a and $6 \mathrm{~b}$, respectively, for men and women. The tables report the results of additional models, including counterfactuals without spillover effects. The shaded areas in the figures indicate the range (from the $5^{\text {th }}$ to the $95^{\text {th }}$ percentile) of variation in minimum wages in the base (red area) and end (blue area) years.

As in Lee (1999), spillover effects substantially increase the contribution of the decline in the real minimum wage to increasing inequality over the 1979-1988 period (see Figure 5). Comparing our results with spillovers to DFL's "tail pasting" method, we predict a counterfactual with far greater mass above the 1979 minimum wage level and less mass at the minimum wage. This occurs because the model accounts for the fact that with spillover effects, some of the observed 1988 mass below the 1979 minimum wage level results from lower spillover effects and moves above the 1979 minimum wage level in the counterfactual. For women, accounting for these spillovers is particularly important. It doubles the increase in the standard deviation of log wages and the Gini coefficient explained by this institutional factor.

For men, the decline in the unionization rate explains a large share of the declining wage density in the middle of the distribution between 1979 and 1988 (Figure 5, panel B). Moreover, because the decline in unionization can explain some of the increasing mass in the lower tail of the 1988 distribution, including unionization (and its spillovers) in the model reduces the share of the mass 
explained by the minimum wage. The model with only minimum wage spillovers may therefore overfit the 1979 distribution in the counterfactual. For women, the minimum wage effect still dominates. Combined, changes in these two institutional factors account for 101\% (74\%) of the change in the 5010 wage gap for men (women) between 1979 and 1988.

Between 1988 and 2000 real minimum wages remain relatively constant (see Figure 1). Therefore, the minimum wage cannot explain the decline in inequality at the bottom of the wage distribution (the decline in the 50-10 gap). However, the decline in unionization explains some of the changing mass in the middle of the distribution and accounts for a large share of the increase in the 9050 gap. Accounting for union spillovers doubles the share of the increase in the 90-50 wage gap explained by unions. This result is consistent with the hump-shaped union threat effects discussed earlier.

Minimum wages rise across a number of states between 2000 and 2017. Figure 7 (Panel A) shows that spillover effects can explain some of the wage gains above the 2017 minimum wage values. For men, declining unionization continues to explain a share of the declining mass in the middle of the distribution, and taken together, both institutional factors explain $99 \%$ of the decline in $50-10$ wage gap over this period. Women experience very little change in the 50-10 gap over this period.

As in DFL, de-unionization has a modest impact on the female wage distribution, in large part because unionization declines much less for women than men. Table 1 shows a relatively modest 6 percentage point decline in unionization rate among women, compared to a 21 percentage points decline for men. Unsurprisingly, we find the largest effects of declining unionization among men, in particular between 1979 and $1988 .{ }^{32}$ Moreover, as the unionization rate declines, so does the impact of unions on the wage distribution coming largely from a decline in the unions' threat effect. Over the entire 1979 to 2017 period, declining unionization explains close to $40 \%$ of the increase in the 90-50 wage differential for men, with spillover effects accounting for about half of the union effect. Overall,

\footnotetext{
${ }^{32}$ In the case of men, the contribution of de-unionization to the growth of inequality is very similar to recent estimates in Card, Lemieux, and Riddell (2018). Table 6a shows that de-unionization (without spillover effects) accounts for 0.014 of the 0.118 increase in the standard deviation of log wages between 1979 and 2017. Using a different approach (counterfactual variances in absence of unionization) for a different period (1973 to 2015), Card, Lemieux, and Riddell (2018) find that de-unionization accounts for 0.015 of the 0.121 increase in the standard deviation of log wages (their variance estimates reported in Table 1 have been transformed in standard deviations). In the case of women, like Card, Lemieux, and Riddell (2018), we find only small effects of de-unionization on changes in inequality in most periods. One exception is that Card, Lemieux, and Riddell (2018) find a more substantial equalizing effect of unions on female wage inequality in 2015 than in other years. We are unsure of the source of difference between the two studies and suspect it has to do with the control variables used in the estimation (we control for industries and occupation while they do not).
} 
our model explains 53\% (28\%) of the increase in the standard deviation of log wages for men (women) and 49\% (27\%) of the increase in the Gini coefficient between 1979 and 2017.

Our results on the contribution of unions to changes in inequality echo those of Farber et al. (2020) who consider a longer time period. Using different data and estimation methods, they find that the direct effect of unionization accounts for 46 percent of the decline in the 90-10 gap between 1936 and 1968, and 16 percent of its increase between 1968 and 2014. The latter figure is similar to our finding that the direct effect de-unionization accounts for 13 percent ( 0.043 out of a 0.322 change in Panel D of Table 6a) of the growth in the 90-10 gap for men between 1979 and 2017. Like us, Farber et al. (2020) also find that spillover effects substantially increase the role of unions in the change in inequality. Taken together, these evidences support the conjecture of Freeman (1996) that spillover effects magnify the effect of de-unionization on inequality growth.

\section{Conclusion}

This paper uses an estimation strategy based on distribution regressions to quantify the contribution of union and minimum wage spillover effects to U.S. wage inequality growth over the 1979-2017 period. The first important finding is that the continuing decline in unionization from 1988 onwards has contributed to continuing wage inequality growth, especially in the upper middle of the distribution. A second important finding is that accounting for spillover effects substantially increases the contribution of both types of institutional changes to wage inequality. These findings confirm and strengthen DFL's conclusion that labor market institutions have played a central role in U.S. wage inequality dynamics since the late 1970s. Our analysis of the impact of minimum wages with spillover effects over a timeperiod spanning more than 35 years also allows us to understand better why previous findings - Lee (1999) and Autor, Manning, and Smith (2016) - may appear contradictory at first blush. The period from 1979 (or indeed 1973) to 1988 saw a substantial (30 percent) and permanent decline in the value of the federal minimum wage, which was the prevailing one in almost all states at the time. By contrast, after 2005, many states increased their minimum wages above the federal one, resulting in smaller and often transitory changes in the effective minimum wage for a large fraction of the workforce. These important differences in the magnitude and persistence of minimum wage changes

over time may help explain why Lee (1999) found larger spillover effects in the pre-1990 period, while Autor, Manning, and Smith (2016) found smaller effects in more recent years. Recent research by Aaronson et al. (2018) suggests that the dynamic employment response to minimum wage changes 
depends on these changes' magnitude and persistence. Improved understanding of how changes in the wage distribution depend on the dynamics of minimum wage changes should be an important topic of future research.

Likewise, it would be useful to understand better the economic forces behind the spillover effects of unionization estimated in this paper. We interpret these findings as evidence of (declining) union threat effects. An alternative interpretation is that that non-union firms that compete with higherpaying union firms need to pay higher wages in imperfectly competitive labor markets than if there were no union employers in their relevant market. ${ }^{33}$ In this setting, the rate of unionization positively impacts non-union wages, even if there is no longer a threat of unionization. Consistent with this view, Benmelech, Bergman, and Kim (2018) find that firms' market power tends to depress wages, but this connection is substantially weaker when the unionization rate is higher. Future research based on rich employer-employee data could help better understand the connection between the wages paid by union and non-union firms, and shed light on the mechanisms behind the union spillover effects documented in this paper.

${ }^{33}$ Card et al. (2018) and Lamadon et al. (2018) present models with imperfect competition where firms pay wages that depend on an index of the wages paid by their competitors. See also Manning (2003). 


\section{REFERENCES}

Aaronson, Daniel, Eric French, Isaac Sorkin and Ted To. "Industry dynamics and the minimum wage: a putty-clay approach.” International Economic Review 59, no. 1 (2018): 51- 84, 2018.

Acemoglu, Daron, and David Autor. "Skills, tasks and technologies: Implications for employment and earnings." In Handbook of Labor Economics, vol. 4, pp. 1043-1171. Elsevier, 2011.

Autor, David, H., David Dorn, and Gordon H. Hanson. "The China Syndrome: Local Labor Market Effects of Import Competition in the United States," American Economic Review 103, no. 6 (2013), 2121-2168.

Autor, David H., Alan Manning, and Christopher L. Smith. "The contribution of the minimum wage to US wage inequality over three decades: a reassessment." American Economic Journal: Applied Economics 8, no. 1 (2016): 58-99.

Biasi, Barbara, and Heather Sarsons. "FlexibleWages, Bargaining, and the Gender Gap," (2019) Paper presented at the AEA 2020.

Benmelech, Efraim, Nittai Bergman, and Hyunseob Kim. "Strong employers and weak employees: How does employer concentration affect wages?" Working Paper No. 24307. National Bureau of Economic Research, 2018.

Bound, John, and Alan B. Krueger. "The extent of measurement error in longitudinal earnings data: Do two wrongs make a right?" Journal of Labor Economics 9, no. 1 (1991): 1-24.

Brochu, Pierre, David A. Green, Thomas Lemieux, and James Townsend. "The Minimum Wage, Turnover, and the Shape of the Wage Distribution.” Working Paper, 2018. 
Butcher, Tim, Richard Dickens, and Alan Manning. "Minimum wages and wage inequality: some theory and an application to the UK." LSE Center for Economic Performance Discussion Papers 1177 (2012).

Card, David. "The effect of unions on the structure of wages: A longitudinal analysis." Econometrica 64, no. 4 (1996): 957-979.

Card, David, Ana Rute Cardoso, Joerg Heining, and Patrick Kline. "Firms and Labor Market Inequality: Evidence and Some Theory.” Journal of Labor Economics 36, no. 1 (2018): S13-S70.

Card, David, and Alan B. Krueger. Myth and Measurement: The New Economics of the Minimum Wage. Princeton University Press, 1995.

Card, David, Thomas Lemieux, and W. Craig Riddell. "Unions and wage inequality." Journal of Labor Research 25, no. 4 (2004): 519-559.

Card, David, Thomas Lemieux, and W. Craig Riddell. "Unions and Wage Inequality: The Roles of Gender, Skill and Public Sector Employment." NBER Working paper No. 25313, November 2018.

Cengiz, Doruk, Arindrajit Dube, Attila Lindner, and Ben Zipperer. "The effect of minimum wages on low-wage jobs." Quarterly Journal of Economics 134, no. 3 (2019): 1405-1454.

Chetverikov, Denis, Bradley Larsen, and Christopher Palmer. "IV quantile regression for group-level treatments, with an application to the distributional effects of trade." Econometrica 84, no. 2 (2016): 809-833.

Chernozhukov, Victor, Iván Fernández-Val, and Blaise Melly. "Inference on counterfactual distributions." Econometrica 81, no. 6 (2013): 2205-2268.

Denice, Patrick and Jake Rosenfeld. "Unions and nonunion pay in the United States, 1977-2015." Sociological Science 5 (2018): 541-561. 
DiNardo, John, Nicole M. Fortin, and Thomas Lemieux. "Labor market institutions and the distribution of wages, 1973-1992: A semiparametric approach" Econometrica 64, no. 5 (1996): 10011044

Doyle, Joseph Jr. "Employment effects of a minimum wage: A density discontinuity design revisited." MIT working paper, 2006.

Dube, Arindrajit, Laura Giuliano, and Jonathan Leonard. "Fairness and Frictions: Impact of Unequal Raises on Quit Behavior.” American Economic Review 109, no. 2 (2019): 620-663

Dube, Arindrajit, Alan Manning, and Suresh Naidu. "Monopsony and Employer Mis-optimization Explain Why Wages Bunch at Round Numbers.” NBER Working Paper No. 24991, September 2018.

Dustmann, Christian, Attila Lindner, Uta Schönberg, Matthias Umkehrer, and Philipp vom Berge. “Reallocation Effects of the Minimum Wage.” CReAM Discussion Paper No. 07/20, 2020

Ellwood, David T., and Glenn Fine. "The impact of right-to-work laws on union organizing." Journal of Political Economy 95, no. 2 (1987): 250-273.

Farber, Henry. "Nonunion wage rates and the threat of unionization." ILR Review 58, no. 3 (2005): $335-352$.

Farber, Henry. "Union organizing decisions in a deteriorating environment: the composition of representation elections and the decline in turnout." ILR Review 68, no. 5 (2015): 1126-1156.

Farber, Henry S., Daniel Herbst, Ilyana Kuziemko, and Suresh Naidu. Unions and Inequality Over the Twentieth Century: New Evidence from Survey Data. NBER Working Paper 24587, 2018.

Feigenbaum, James, Alexander Hertel-Fernandez, and Vanessa Williamson. "From the Bargaining Table to the Ballot Box: Political Effects of Right to Work Laws.” NBER Working Paper 24259, 2018. 
Firpo, Sergio, Nicole M. Fortin, and Thomas Lemieux. "Unconditional quantile regressions." Econometrica 77, no. 3 (2009): 953-973.

Firpo, Sergio, Nicole M. Fortin, and Thomas Lemieux. "Decomposing wage distributions using recentered influence function regressions." Econometrics 6, no. 2 (2018): 28.

Foresi, Silverio, and Franco Peracchi. "The conditional distribution of excess returns: An empirical analysis." Journal of the American Statistical Association 90, no. 430 (1995): 451-466.

Fortin, Nicole M., Thomas Lemieux, and Neil Lloyd. "Labor Market Institutions and the Distribution of Wages: The Role of Spillover Effects.” UBC Working Paper, February 2019.

Fortin, Nicole M., and Thomas Lemieux. "Rank regressions, wage distributions, and the gender gap." Journal of Human Resources 33, no. 3 (1998): 610-643.

Freeman, Richard. "How much has de-unionization contributed to the rise in male earnings inequality?" In Uneven Tides: Rising Inequality in America, edited by Danziger, Sheldon, and Peter Gottschalk, pp. 133-63. New York: Russell Sage Foundation, 1993.

Freeman, Richard B. "Labor market institutions and earnings inequality" New England Economic Review, Special Issue (May/June 1996): 157-172

Freeman, Richard B., and James L. Medoff. "The impact of the percentage organized on union and nonunion wages." The Review of Economics and Statistics 63, no. 4 (1981): 561-572.

Grossman, Jean Baldwin. "The impact of the minimum wage on other wages." Journal of Human Resources 18, no. 3 (1983): 359-378.

Haanwinckel, Daniel. "Supply, demand, institutions, and firms: a theory of labor market sorting and the wage distribution." UCLA Working Paper, 2020 
Hirsch, Barry T., and Edward J. Schumacher. "Match bias in wage gap estimates due to earnings imputation." Journal of Labor Economics 22, no. 3 (2004): 689-722.

Jales, Hugo. "Estimating the effects of the minimum wage in a developing country: A density discontinuity design approach." Journal of Applied Econometrics 33, no. 1 (2018): 29-51.

Lamadon, Thibaut, Magne Mogstad, and Bradley Setzler. "Imperfect Competition and Rent Sharing in the U.S. Labor Market.” University of Chicago Working Paper, 2018

Lee, David S. "Wage inequality in the United States during the 1980s: Rising dispersion or falling minimum wage?" The Quarterly Journal of Economics 114, no. 3 (1999): 977-1023.

Lemieux, Thomas. "Increasing residual wage inequality: Composition effects, noisy data, or rising demand for skill?" American Economic Review 96, no. 3 (2006): 461-498.

Lewis, H. Gregg. Unionism and Relative Wages in the United States: An Empirical Inquiry. Chicago: University of Chicago Press, 1963.

Manning, Alan. Monopsony in motion. Princeton University Press, 2003.

Moore, William J., Robert J. Newman, and James Cunningham. "The effect of the extent of unionism on union and nonunion wages." Journal of Labor Research 6, no. 1 (1985): 21-44.

Podgursky, Michael. "Unions, establishment size, and intra-industry threat effects." ILR Review 39, no. 2 (1986): 277-284.

Rosen, Sherwin. "Trade union power, threat effects and the extent of organization." The Review of Economic Studies 36, no. 2 (1969): 185-196. 
Rosenfeld, Jake, Patrick Denice, and Jennifer Laird. "Union decline lowers wages of nonunion workers" Economic Policy Institute, 2016

Taschereau-Dumouchel, Mathieu. “The Union Threat.” Review of Economic Studies 87, no. 6 (2020): 2859-92.

Teulings, Coen N. "Aggregation bias in elasticities of substitution and the minimum wage paradox." International Economic Review 41, no. 2 (2000): 359-398. 


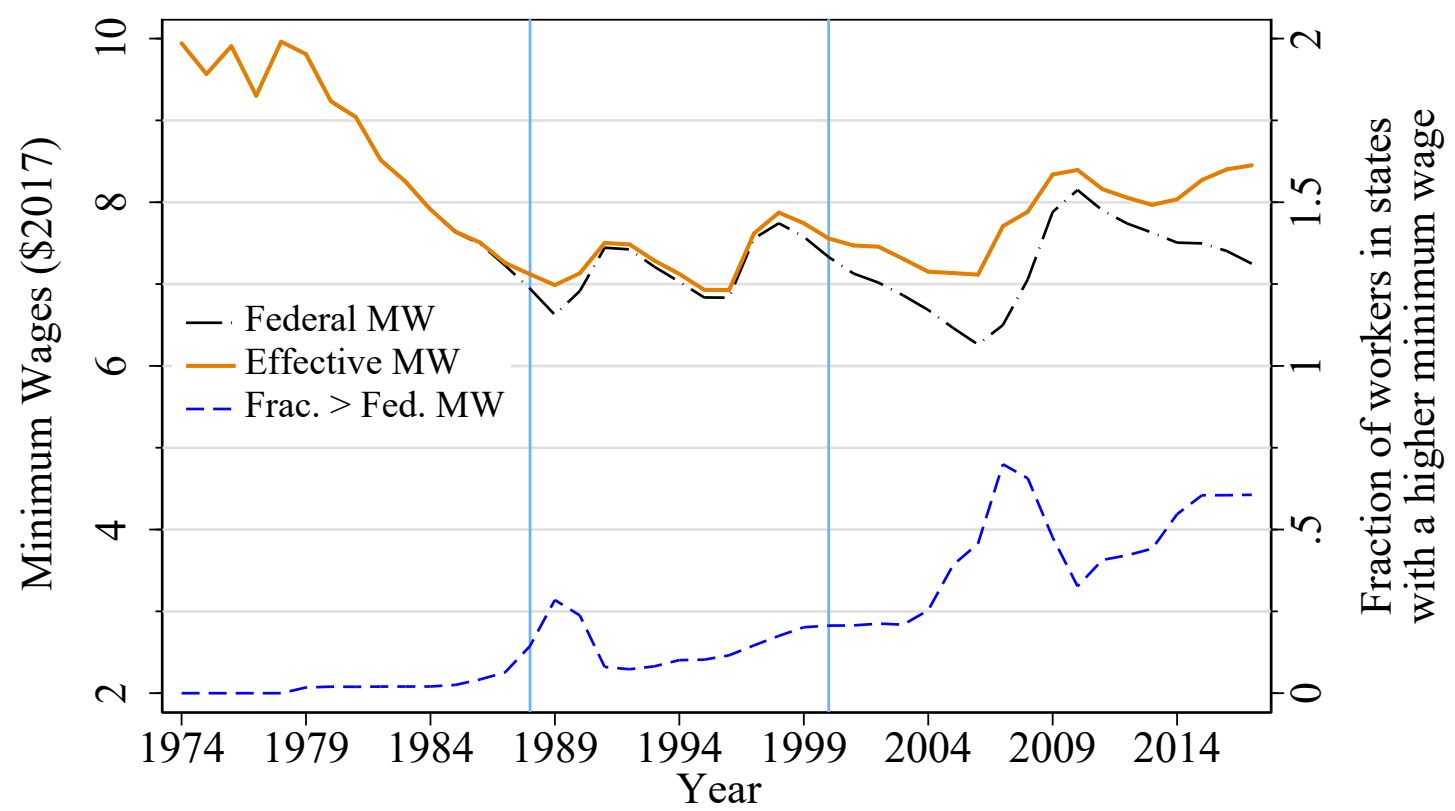

Figure 1. Real Value (\$2017) of the Minimum Wage (MW) and Fraction of Workers in States with a Higher Minimum

NOTE: The federal minimum wage is based on official monthly federal minimum wage levels. The effective minimum wage is the maximum of the federal and state minimum wage, where states are weighted according to their relative employed populations, using CPS data. The fraction of workers residing in states with minimum wages above the federal level is calculated using the CPS population weights. The vertical lines demark the periods of analysis: 1979-1988, 1988-2000, and 2000-2017. 
A. Low-unionization industries

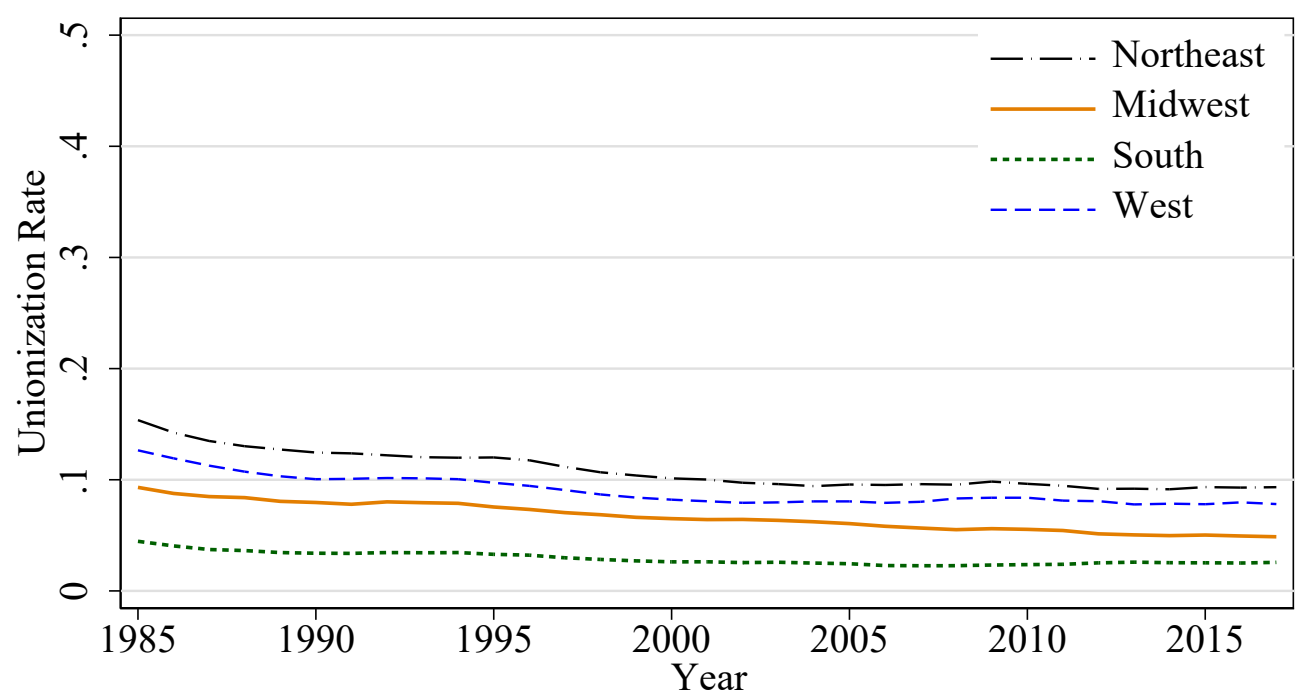

B. High-unionization industries

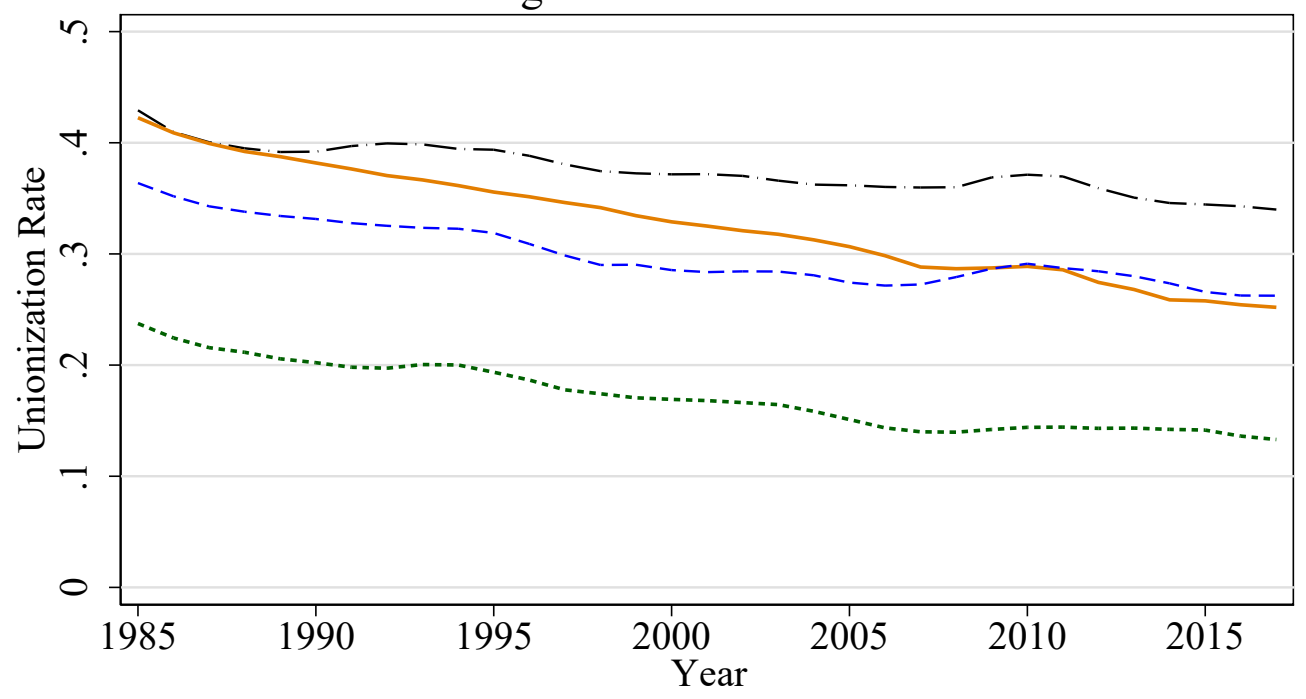

Figure 2. Trends in Unionization Rates across Census Bureau Division, and Low- and High-Unionization Industries - Men and Women Combined

NOTE: Figure depicts a three-year moving average of the coverage rate of both private and public sector salaried workers by Census Bureau Division, using data from the 1983-2017 CPS. High unionization industries include construction, manufacturing, transportation and utilities, education services, and public administration. Low unionization industries include primary sector, wholesale and retail, financial services, business and professional services, health and welfare services, and other services. 
A. $1979-1988$

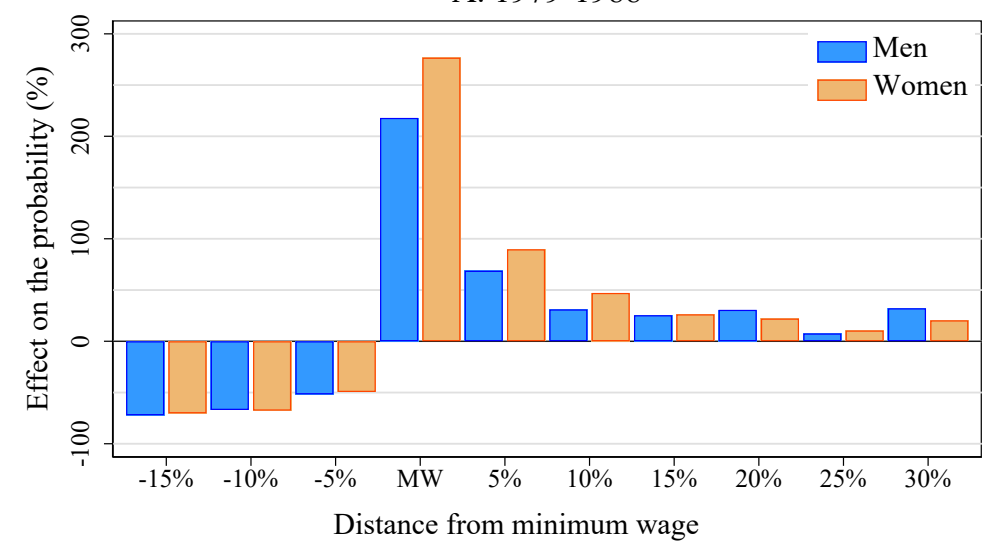

B. $1988-2000$

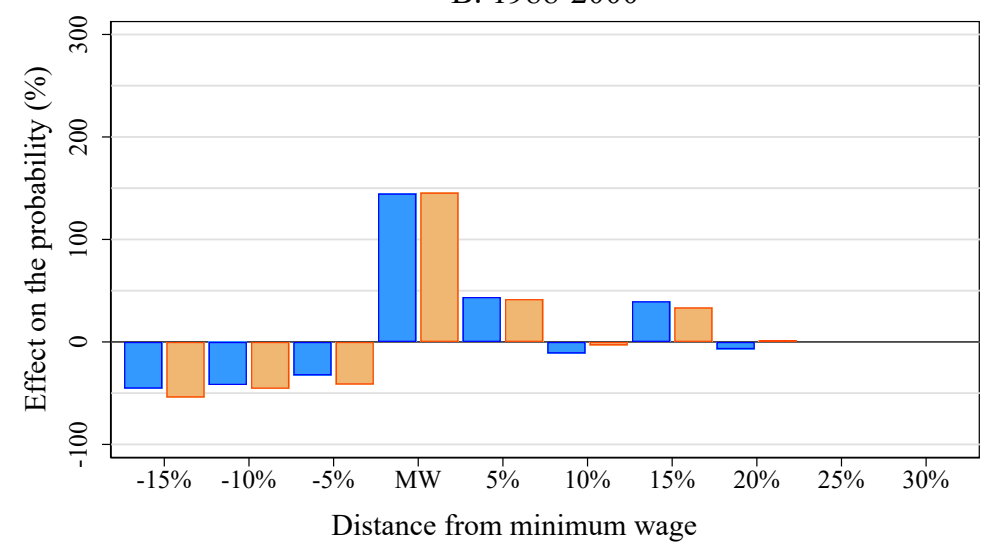

C. $2000-2017$

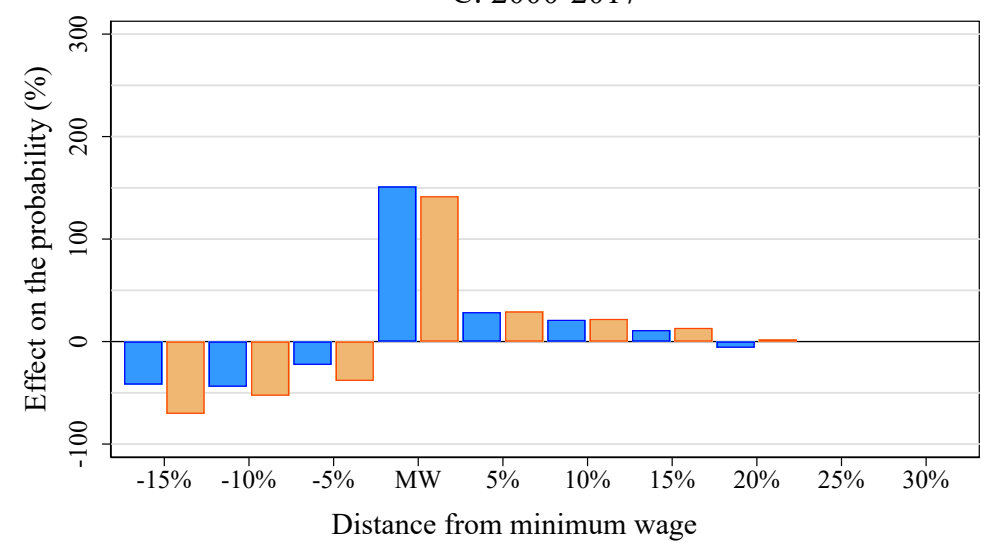

Figure 3. Marginal Effects of Minimum Wages

NOTE: Marginal effects of the minimum wage on the $(\log )$ wage distribution are calculated using the difference in the average predicted probability of at each wage-bin under the median minimum wage (during the time period), relative to the counterfactual of no minimum wage. 

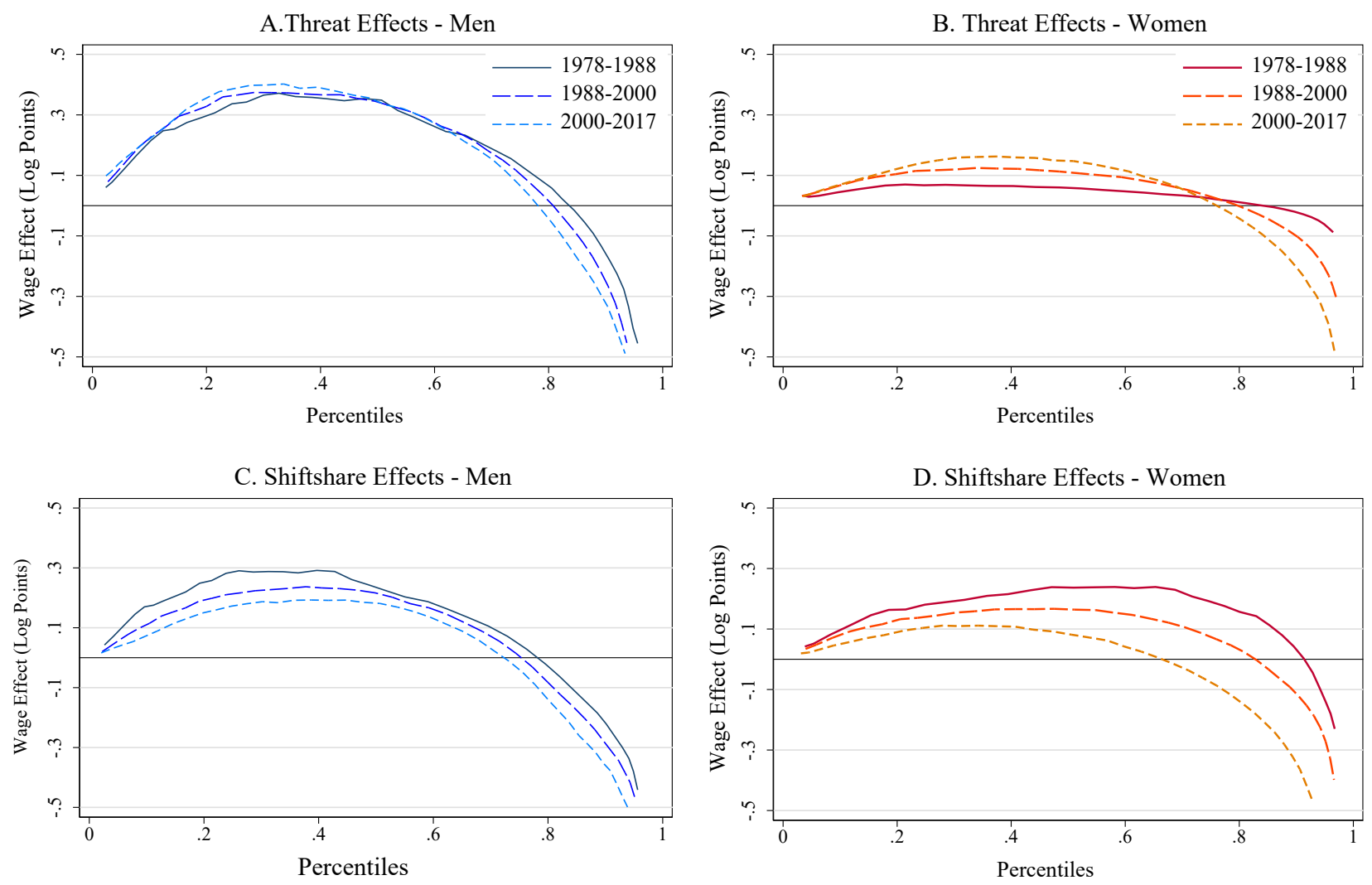

Figure 4. Marginal Effects of a 1\% Increase in the Unionization Rate

NOTE: The threat effects indicate the wages changes (log points) in the non-union distribution in response to an increase in union coverage of $1 \%$, keeping the union and non-union distributions unchanged. The effects are estimated as the average changes in the predicted probability under the observed coverage rate, and a coverage rate $1 \%$-point higher. 


\section{A. Minimum Wages Effects with Spillovers}
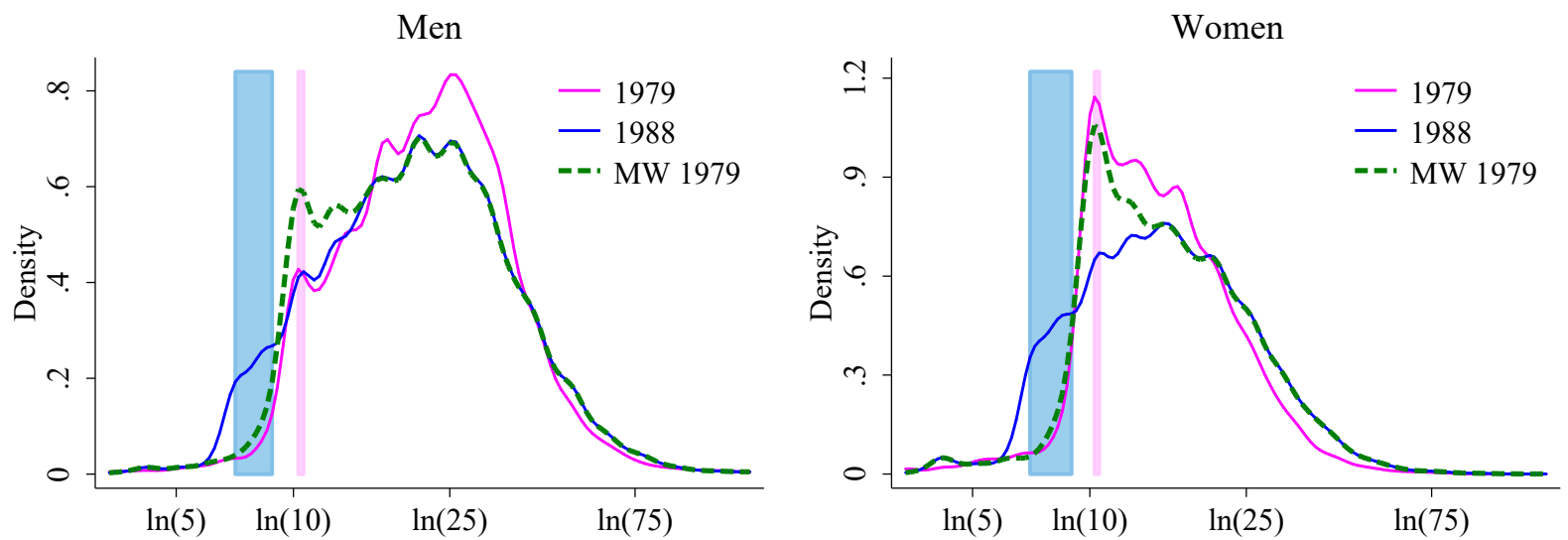

B. Adding Union Wages Effects with Spillovers
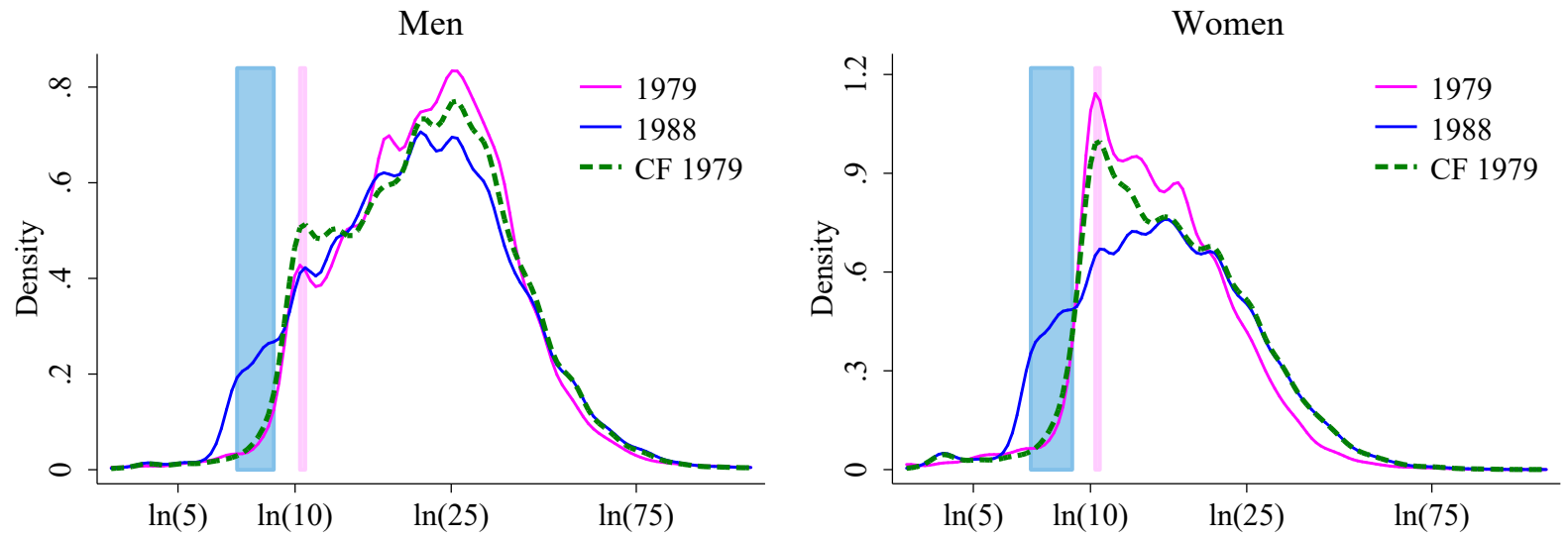

Figure 5. Counterfactual Densities 1979-1988

NOTE: In Panel A, "MW 1979" depicts the 1988 wage density under the counterfactual that the minimum wage level remained at its 1979 level. In Panel B, "CF 1979" depicts the counterfactual density for 1988 if the minimum wage and unionization levels remained at their 1979 levels. The shaded areas of the corresponding color depict the range of state minimum wage levels for that year. 
A. Minimum Wages Effects with Spillovers
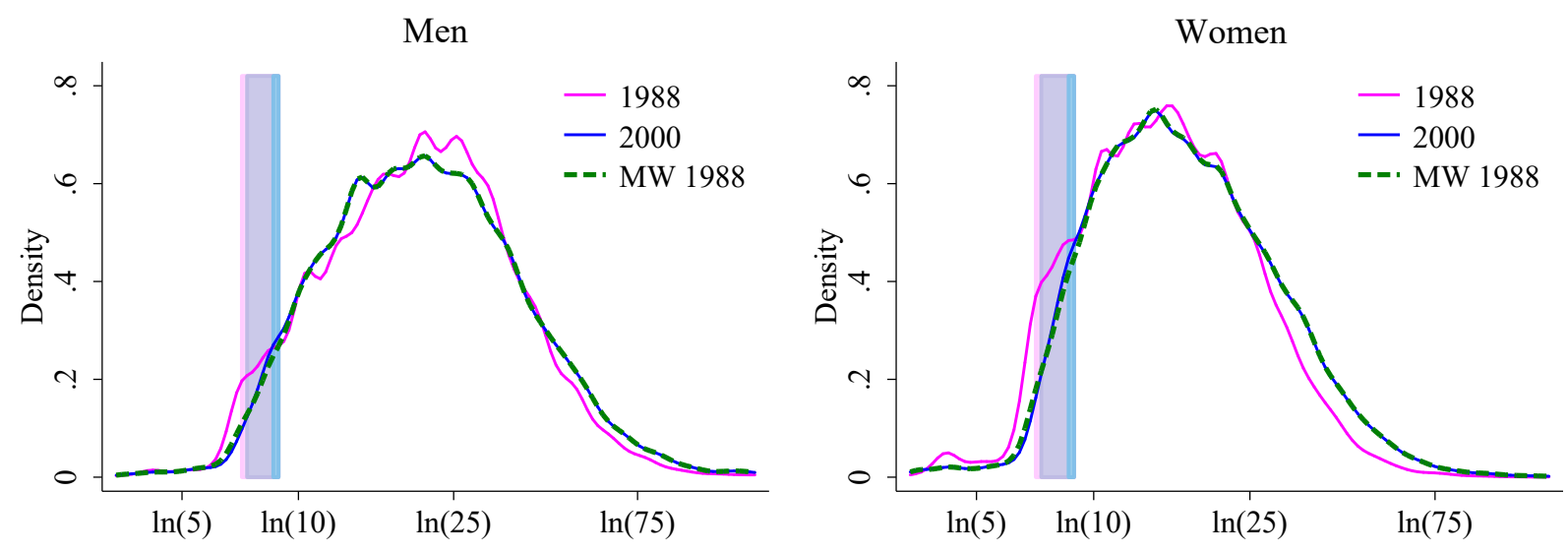

B. Adding Union Wages Effects with Spillovers
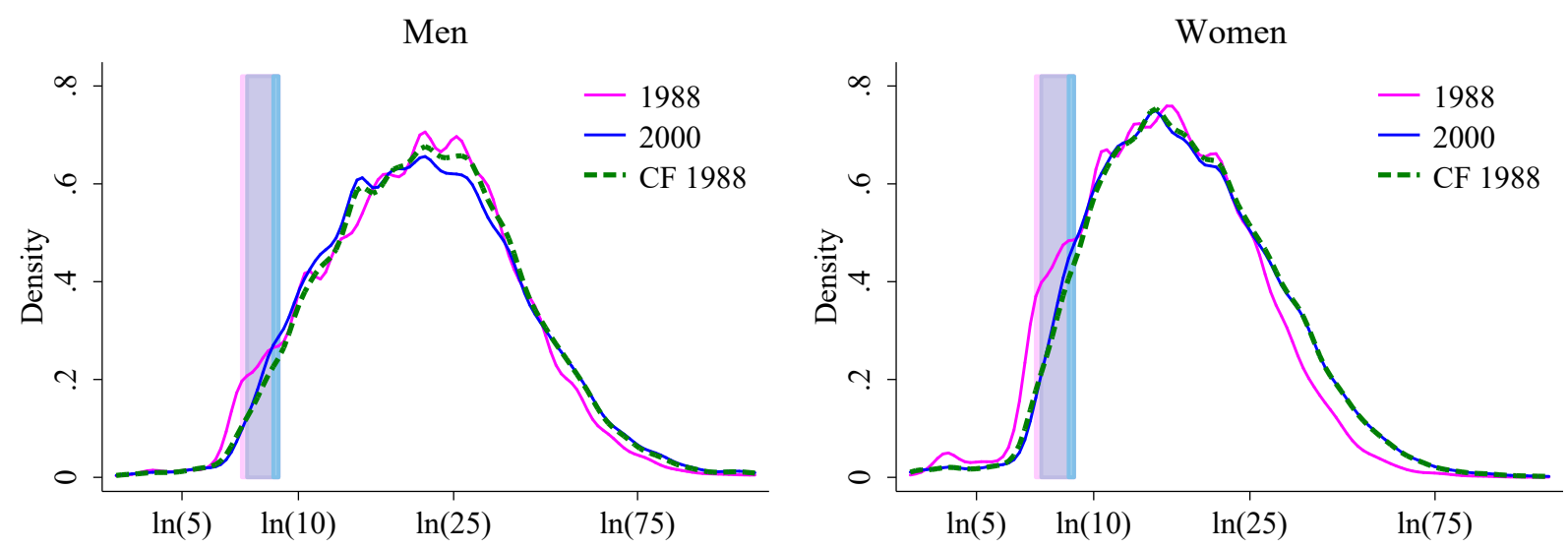

Figure 6. Counterfactual Densities 1988-2000

NOTE: In Panel A, "MW 1988" depicts the 2000 wage density under the counterfactual that the minimum wage level remained at its 1988 level. In Panel B, "CF 1988" depicts the counterfactual density for 2000 assuming the minimum wage and unionization levels remained at their 1988 levels. The shaded areas of the corresponding color depict the range of state minimum wage levels for that year. 
A. Minimum Wages Effects with Spillovers

Men

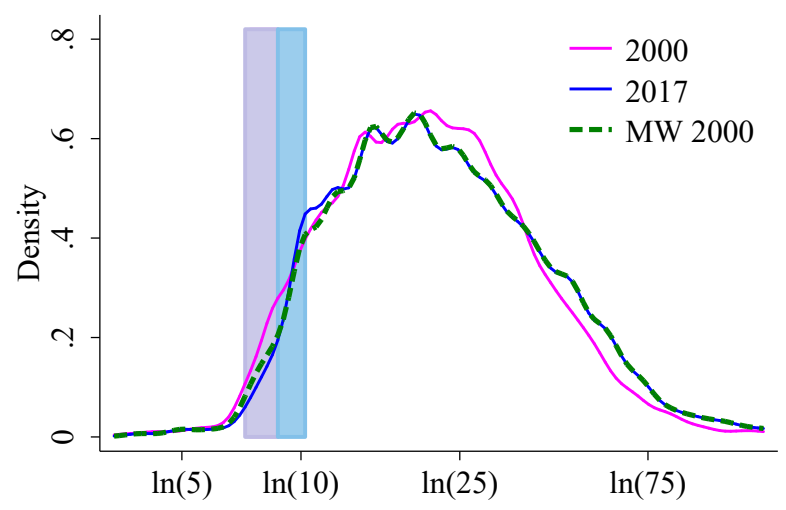

Women

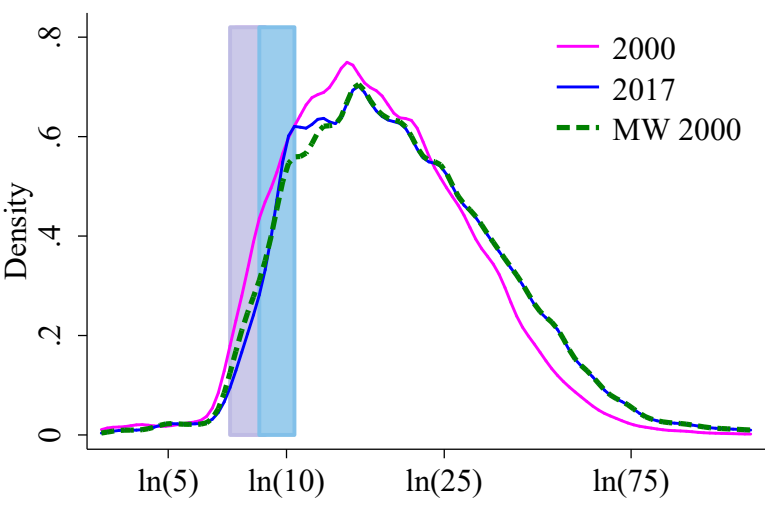

B. Adding Union Wages Effects with Spillovers

Men

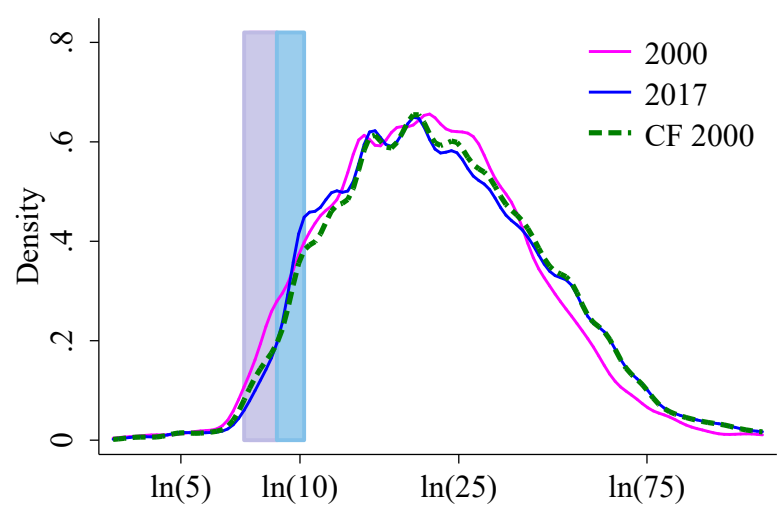

Women

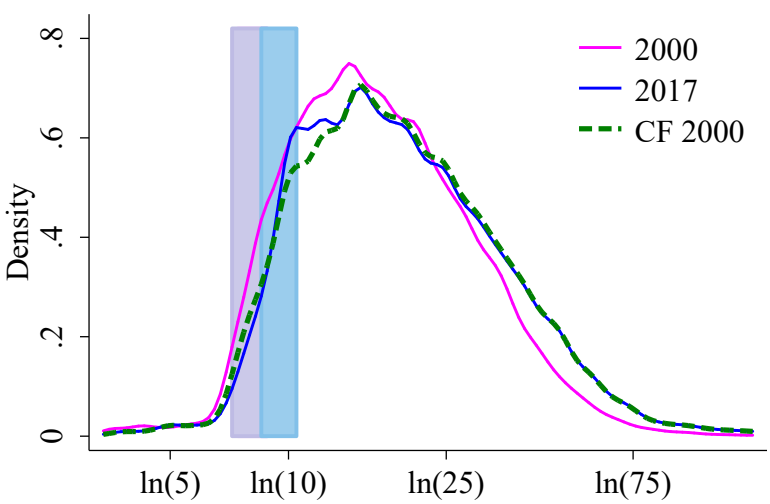

Figure 7. Counterfactual Densities 2000-2017

NOTE: In Panel A, "MW 2000" depicts the 2017 wage density under the counterfactual that the minimum wage level remained at its 2000 level. In Panel B, "CF 2000" depicts the counterfactual density for 2017 if minimum wages and unionization levels remained at their 2000 levels. The shaded areas of the corresponding color depict the range of state minimum wage levels for that year. 
Table 1 - Inequality Measures and Descriptive Statistics

\begin{tabular}{lcccc}
\hline Year & 1979 & 1988 & 2000 & 2017 \\
\hline & A: Men & & & \\
$90-10$ & 1.281 & 1.452 & 1.521 & 1.608 \\
$90-50$ & 0.588 & 0.693 & 0.793 & 0.901 \\
$50-10$ & 0.693 & 0.759 & 0.728 & 0.707 \\
Std(log wages) & 0.249 & 0.326 & 0.357 & 0.413 \\
Gini & 0.279 & 0.324 & 0.355 & 0.392 \\
Theil & 0.142 & 0.199 & 0.267 & 0.326 \\
Unemployment rate & 0.051 & 0.055 & 0.040 & 0.045 \\
Unionization rate & 0.337 & 0.229 & 0.168 & 0.127 \\
No. of obs. & 76213 & 74020 & 53037 & 46342 \\
\hline & B: Women & & & \\
90-10 & 0.950 & 1.286 & 1.357 & 1.452 \\
90-50 & 0.568 & 0.667 & 0.746 & 0.865 \\
50-10 & 0.382 & 0.619 & 0.611 & 0.588 \\
Std(log wages) & 0.172 & 0.255 & 0.288 & 0.357 \\
Gini & 0.236 & 0.287 & 0.317 & 0.363 \\
Theil & 0.097 & 0.144 & 0.204 & 0.276 \\
Unemployment rate & 0.070 & 0.057 & 0.042 & 0.044 \\
Unionization rate & 0.176 & 0.153 & 0.134 & 0.115 \\
No. of obs. & 62281 & 69292 & 52171 & 45382 \\
\hline
\end{tabular}

Note: 90-10, 90-50, and 50-10 denote corresponding log wage differentials. "No. of obs." is the number of observations in the unallocated sample used to compute inequality measures. The unemployment and unionization rates are based on the full sample (allocated observations included). For 1979 the unionization rate is derived from the matched May-MORG sample. 
Table 2: Minimum Wage Effects Estimated from Distribution Regression Models

\begin{tabular}{|c|c|c|c|c|c|c|}
\hline \multirow[t]{3}{*}{ Wage Bins } & (1) & $(2)$ & (3) & (4) & $(5)$ & (6) \\
\hline & \multicolumn{2}{|c|}{$1979-88$} & \multicolumn{2}{|c|}{$1988-2000$} & \multicolumn{2}{|c|}{$2000-2017$} \\
\hline & Women & Men & Women & Men & Women & Men \\
\hline \multicolumn{7}{|l|}{ Minimum wage effects } \\
\hline More than & -0.018 & -0.025 & -0.011 & 0.011 & -0.030 & 0.010 \\
\hline $10 \%$ below & $(0.004)$ & $(0.005)$ & $(0.019)$ & 0.032 & $(0.019)$ & $(0.020)$ \\
\hline \multirow{2}{*}{$5-10 \%$ below } & -0.016 & -0.014 & 0.000 & 0.012 & -0.006 & 0.004 \\
\hline & $(0.004)$ & $(0.004)$ & $(0.008)$ & $(0.013)$ & $(0.004)$ & $(0.005)$ \\
\hline \multirow[t]{2}{*}{$0-5 \%$ below } & 0.020 & 0.022 & 0.005 & 0.026 & 0.014 & 0.031 \\
\hline & $(0.003)$ & $(0.003)$ & $(0.006)$ & $(0.009)$ & $(0.004)$ & $(0.004)$ \\
\hline \multirow[t]{2}{*}{ At minimum } & 0.557 & 0.494 & 0.341 & 0.324 & 0.329 & 0.293 \\
\hline & $(0.017)$ & $(0.014)$ & $(0.025)$ & $(0.029)$ & $(0.035)$ & $(0.040)$ \\
\hline \multirow[t]{2}{*}{$0-5 \%$ above } & 0.152 & 0.122 & 0.095 & 0.092 & 0.074 & 0.059 \\
\hline & $(0.003)$ & $(0.004)$ & $(0.007)$ & $(0.005)$ & $(0.005)$ & $(0.005)$ \\
\hline \multirow[t]{2}{*}{$5-10 \%$ above } & 0.077 & 0.052 & 0.003 & -0.011 & 0.053 & 0.042 \\
\hline & $(0.002)$ & $(0.003)$ & $(0.006)$ & $(0.004)$ & $(0.004)$ & $(0.003)$ \\
\hline \multirow[t]{2}{*}{$10-15 \%$ above } & 0.038 & 0.033 & 0.057 & 0.061 & 0.024 & 0.016 \\
\hline & $(0.002)$ & $(0.004)$ & $(0.007)$ & $(0.005)$ & $(0.005)$ & $(0.004)$ \\
\hline \multirow[t]{2}{*}{$15-20 \%$ above } & 0.028 & 0.031 & 0.003 & -0.011 & 0.004 & -0.010 \\
\hline & $(0.002)$ & $(0.003)$ & $(0.010)$ & $(0.007)$ & $(0.013)$ & $(0.009)$ \\
\hline \multirow[t]{2}{*}{$20-25 \%$ above } & 0.016 & 0.012 & & & & \\
\hline & $(0.002)$ & $(0.003)$ & & & & \\
\hline \multirow[t]{2}{*}{$25-30 \%$ above } & 0.026 & 0.034 & & & & \\
\hline & $(0.002)$ & $(0.003)$ & & & & \\
\hline \multicolumn{7}{|l|}{ Spikes at integers } \\
\hline Dollar values & 0.081 & 0.083 & 0.077 & 0.077 & 0.063 & 0.057 \\
\hline$(\$ 1$ to $\$ 10)$ & $(0.003)$ & $(0.003)$ & $(0.004)$ & $(0.003)$ & $(0.009)$ & $(0.008)$ \\
\hline \multirow[t]{2}{*}{ Increment at $\$ 5$} & 0.051 & 0.081 & & & & \\
\hline & $(0.004)$ & $(0.005)$ & & & & \\
\hline \multirow[t]{2}{*}{ Increment at $\$ 10$} & & & 0.004 & 0.038 & 0.029 & 0.049 \\
\hline & & & $(0.008)$ & $(0.005)$ & $(0.008)$ & $(0.005)$ \\
\hline No. of obs: & 698122 & 787803 & 715077 & 741043 & 946180 & 955116 \\
\hline
\end{tabular}

Notes: The table reports estimates of the models presented in equation (4) in the text. In addition to the variables presented in the table, all models also control for state, year, and quarter effects, state-specific trends, years of education, a quartic in potential experience, experience-education interactions ( 16 categories plus experience times education), 11 industry categories, 4 occupation categories, and dummy variables for race, marital status, public sector, part-time, and SMSA. Standard errors (clustered at the state level) are in parentheses. 
Table 3. Estimates of Minimum Wage Impacts Along the Wage Distribution

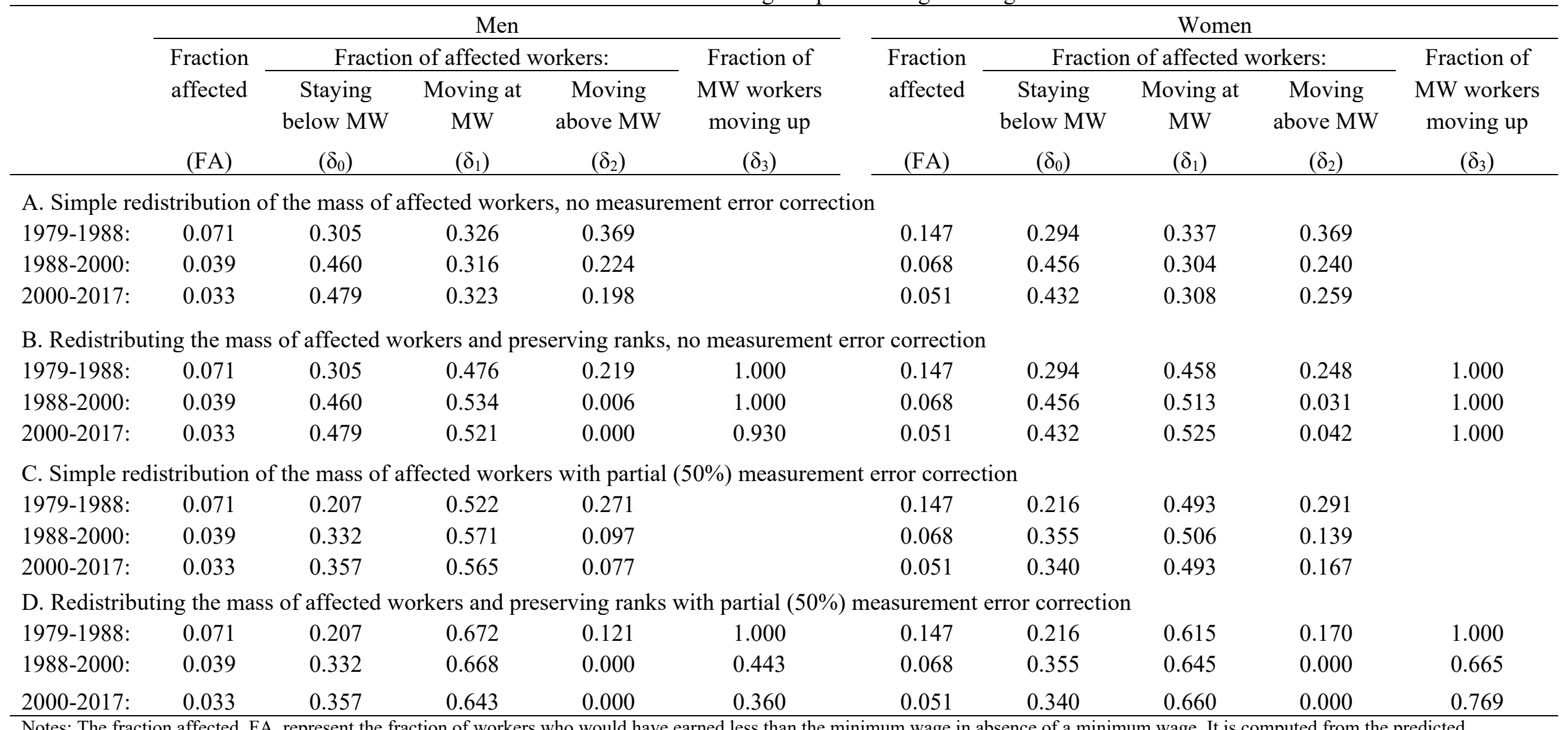

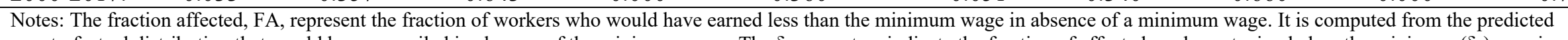

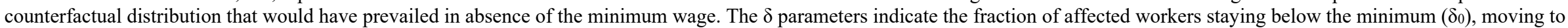
exactly $\left(\delta_{1}\right)$ or above $\left(\delta_{2}\right)$ the minimum, and workers at the minimum wage who move above the minimum $\left(\delta_{3}\right)$. See the text for more details. 
Table 4: OLS Estimates of the Union Threat Effect on Log Wages with Alternative Definitions of the Unionization Rate

\begin{tabular}{|c|c|c|c|c|c|c|c|c|}
\hline \multirow{2}{*}{$\begin{array}{l}\text { Definitions of } \\
\text { Unionization Rate: }\end{array}$} & \multicolumn{4}{|c|}{ Non-union Workers } & \multicolumn{4}{|c|}{ Union Workers } \\
\hline & (1) & (2) & (3) & (4) & $(5)$ & (6) & (7) & (8) \\
\hline \multicolumn{9}{|l|}{ A. $1979-1988$} \\
\hline Industry*state & $\begin{array}{c}0.151 \\
(0.039)\end{array}$ & $\begin{array}{c}0.152 \\
(0.040)\end{array}$ & $\begin{array}{c}0.150 \\
(0.040)\end{array}$ & $\begin{array}{c}0.178 \\
(0.049)\end{array}$ & $\begin{array}{c}0.337 \\
(0.050)\end{array}$ & $\begin{array}{c}0.339 \\
(0.051)\end{array}$ & $\begin{array}{c}0.342 \\
(0.051)\end{array}$ & $\begin{array}{c}0.326 \\
(0.074)\end{array}$ \\
\hline State & & $\begin{array}{l}-0.071 \\
(0.085)\end{array}$ & & & & $\begin{array}{l}-0.149 \\
(0.151)\end{array}$ & & \\
\hline $\begin{array}{l}\text { Broad industry } \\
* \text { state }\end{array}$ & & & & $\begin{array}{l}-0.049 \\
(0.063)\end{array}$ & & & & $\begin{array}{c}0.021 \\
(0.102)\end{array}$ \\
\hline \multicolumn{9}{|l|}{ B. $1988-2000$} \\
\hline Industry*state & $\begin{array}{c}0.123 \\
(0.035)\end{array}$ & $\begin{array}{c}0.125 \\
(0.035)\end{array}$ & $\begin{array}{c}0.125 \\
(0.035)\end{array}$ & $\begin{array}{c}0.135 \\
(0.044)\end{array}$ & $\begin{array}{c}0.337 \\
(0.053)\end{array}$ & $\begin{array}{c}0.341 \\
(0.053)\end{array}$ & $\begin{array}{c}0.344 \\
(0.054)\end{array}$ & $\begin{array}{c}0.221 \\
(0.074)\end{array}$ \\
\hline State & & $\begin{array}{l}-0.152 \\
(0.076)\end{array}$ & & & & $\begin{array}{l}-0.316 \\
(0.141)\end{array}$ & & \\
\hline $\begin{array}{l}\text { Broad industry } \\
* \text { state }\end{array}$ & & & & $\begin{array}{l}-0.020 \\
(0.054) \\
\end{array}$ & & & & $\begin{array}{c}0.203 \\
(0.093) \\
\end{array}$ \\
\hline \multicolumn{9}{|l|}{ C. $2000-2017$} \\
\hline Industry*state & $\begin{array}{c}0.110 \\
(0.038)\end{array}$ & $\begin{array}{c}0.110 \\
(0.038)\end{array}$ & $\begin{array}{c}0.110 \\
(0.038)\end{array}$ & $\begin{array}{c}0.069 \\
(0.052)\end{array}$ & $\begin{array}{c}0.321 \\
(0.053)\end{array}$ & $\begin{array}{c}0.328 \\
(0.055)\end{array}$ & $\begin{array}{c}0.332 \\
(0.055)\end{array}$ & $\begin{array}{c}0.148 \\
(0.093)\end{array}$ \\
\hline State & & $\begin{array}{c}0.013 \\
(0.066)\end{array}$ & & & & $\begin{array}{l}-0.380 \\
(0.134)\end{array}$ & & \\
\hline $\begin{array}{l}\text { Broad industry } \\
* \text { state }\end{array}$ & & & & $\begin{array}{c}0.067 \\
(0.060) \\
\end{array}$ & & & & $\begin{array}{c}0.257 \\
(0.111) \\
\end{array}$ \\
\hline $\begin{array}{l}\text { State*year } \\
\text { dummies }\end{array}$ & No & No & Yes & No & No & No & Yes & No \\
\hline
\end{tabular}

Notes: The models are estimated for men and women pooled together, and include controls for industry-specific trends and the other variables listed in the note to Table 2. The main industry classification (first row of each panel) consists of 11 industry categories. The broad industry classification (third row of each panel) is based on 3 categories. The number of observations for non-union (union) workers in the three periods are 730778 (197150) in 1979-88, 1201295 (254801) in 1988-2000, and 1636092 (265204) in 2000-2017. Standard errors (clustered at the state-industry level) are in parentheses. 
Table 5: Unionization Rate Effects Estimated from Distribution Regression Models

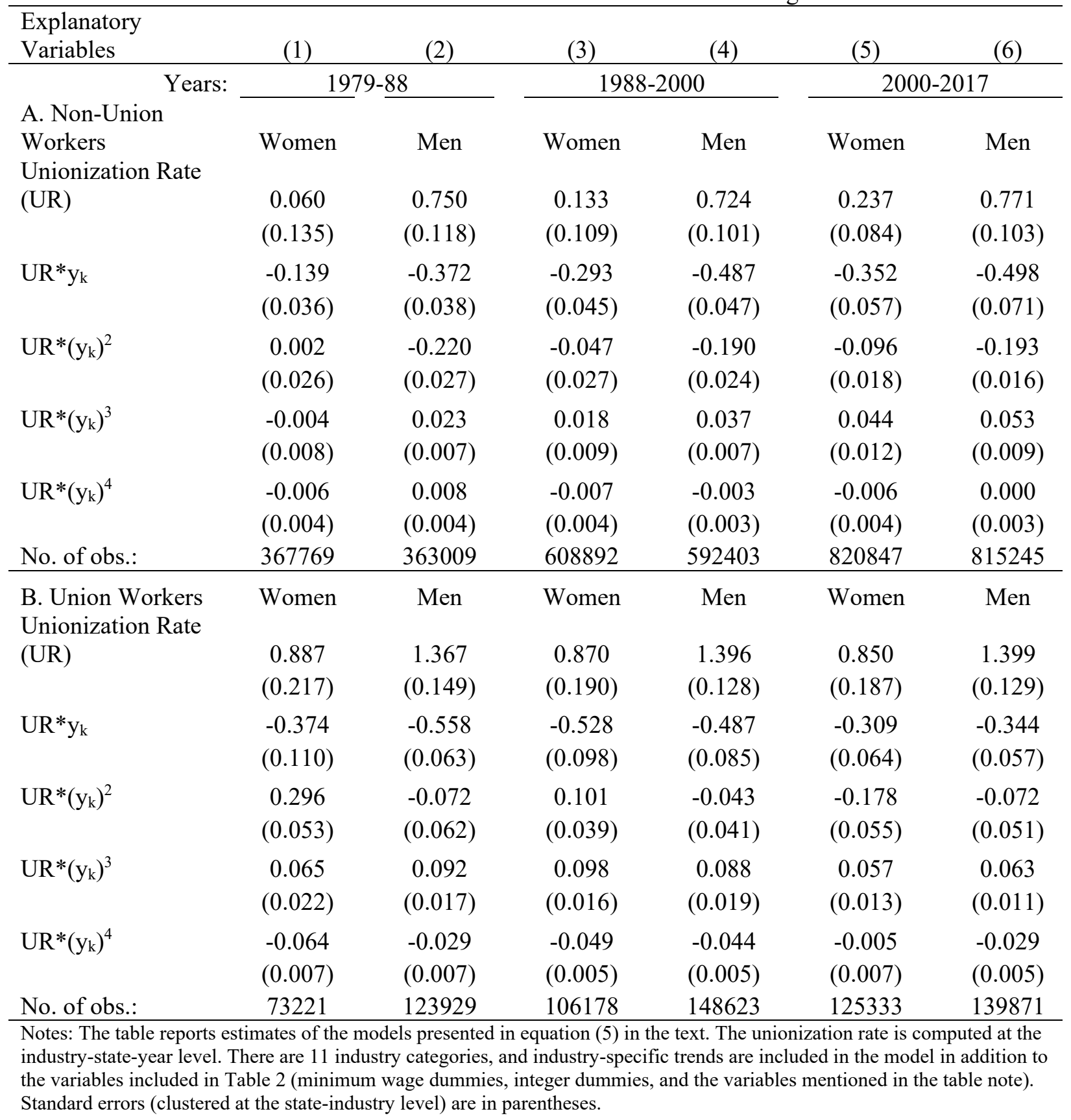


Table 6a. Decomposition Results - Men

\begin{tabular}{|c|c|c|c|c|c|c|c|}
\hline & $(1)$ & $(2)$ & (3) & (4) & $(5)$ & (6) & $(7)$ \\
\hline Inequality & Raw & \multicolumn{2}{|c|}{ Minimum Wages } & \multicolumn{2}{|c|}{ Unions } & \multirow{2}{*}{$\begin{array}{l}\text { Together } \\
\text { w/spill. }\end{array}$} & \multirow{2}{*}{$\begin{array}{l}\text { Percentage } \\
\text { Explained }\end{array}$} \\
\hline Measures & Changes & $\begin{array}{c}\text { no } \\
\text { spill. }\end{array}$ & w/spill. & $\begin{array}{c}\text { no } \\
\text { spill. }\end{array}$ & w/spill. & & \\
\hline \multicolumn{8}{|l|}{ A: $1979-1988$} \\
\hline $90-10$ & 0.213 & 0.089 & 0.126 & 0.027 & 0.050 & 0.159 & $75 \%$ \\
\hline $90-50$ & 0.119 & 0.006 & 0.004 & 0.036 & 0.062 & 0.065 & $55 \%$ \\
\hline $50-10$ & 0.094 & 0.083 & 0.122 & -0.009 & -0.012 & 0.094 & $101 \%$ \\
\hline Std(log wages) & 0.073 & 0.019 & 0.032 & 0.009 & 0.017 & 0.050 & $69 \%$ \\
\hline Gini & 0.041 & 0.007 & 0.011 & 0.008 & 0.016 & 0.026 & $64 \%$ \\
\hline Theil & 0.041 & 0.007 & 0.011 & 0.008 & 0.017 & 0.027 & $66 \%$ \\
\hline \multicolumn{8}{|l|}{ B: $1988-2000$} \\
\hline $90-10$ & 0.015 & 0.004 & 0.004 & 0.011 & 0.026 & 0.031 & $212 \%$ \\
\hline $90-50$ & 0.090 & 0.001 & 0.001 & 0.018 & 0.037 & 0.039 & $43 \%$ \\
\hline $50-10$ & -0.075 & 0.003 & 0.002 & -0.007 & -0.011 & -0.008 & $10 \%$ \\
\hline Std(log wages) & 0.013 & 0.001 & 0.000 & 0.004 & 0.011 & 0.011 & $81 \%$ \\
\hline Gini & 0.018 & 0.001 & 0.000 & 0.003 & 0.009 & 0.009 & $52 \%$ \\
\hline Theil & 0.023 & 0.001 & 0.000 & 0.004 & 0.011 & 0.012 & $49 \%$ \\
\hline \multicolumn{8}{|l|}{$C: 2000-2017$} \\
\hline $90-10$ & 0.095 & -0.007 & -0.013 & 0.004 & 0.012 & -0.001 & $-1 \%$ \\
\hline $90-50$ & 0.121 & 0.001 & 0.001 & 0.011 & 0.024 & 0.025 & $21 \%$ \\
\hline $50-10$ & -0.027 & -0.008 & -0.014 & -0.007 & -0.011 & -0.026 & $99 \%$ \\
\hline Std(log wages) & 0.032 & -0.002 & -0.004 & 0.002 & 0.005 & 0.002 & $5 \%$ \\
\hline Gini & 0.020 & 0.000 & -0.001 & 0.002 & 0.004 & 0.004 & $18 \%$ \\
\hline Theil & 0.019 & 0.000 & -0.001 & 0.002 & 0.006 & 0.005 & $26 \%$ \\
\hline \multicolumn{8}{|l|}{ D: $1979-2017$} \\
\hline $90-10$ & 0.322 & 0.086 & 0.117 & 0.043 & 0.088 & 0.189 & $59 \%$ \\
\hline $90-50$ & 0.330 & 0.008 & 0.006 & 0.065 & 0.123 & 0.129 & $39 \%$ \\
\hline $50-10$ & -0.008 & 0.078 & 0.111 & -0.023 & -0.034 & 0.060 & - \\
\hline Std(log wages) & 0.118 & 0.018 & 0.028 & 0.014 & 0.034 & 0.063 & $53 \%$ \\
\hline Gini & 0.079 & 0.007 & 0.011 & 0.013 & 0.029 & 0.039 & $49 \%$ \\
\hline Theil & 0.084 & 0.007 & 0.010 & 0.014 & 0.034 & 0.044 & $52 \%$ \\
\hline
\end{tabular}

Note: Column (1) shows the raw changes in inequality measures. Each subsequent column corresponds to a different counterfactual with either minimum wages or unionization turned back to their base period value. Columns (2) and (3) show the contribution of minimum wage changes without ("tail-pasting" only) and with spillover effects. Likewise, columns (4) and (5) show the contribution of changes in unionization without ("shiftshare" effect only) and then with spillover effects (threat effects). Column (6) shows the contribution of changes in both the minimum wage and unionization (including spillover effects). Column (7) shows how much of the overall change (column 1) can be explained by institutional change (column 6). 
Table 6b. Decomposition Results - Women

\begin{tabular}{|c|c|c|c|c|c|c|c|}
\hline & $(1)$ & $(2)$ & (3) & (4) & $(5)$ & (6) & $(7)$ \\
\hline Inequality & Raw & \multicolumn{2}{|c|}{ Minimum Wages } & \multicolumn{2}{|c|}{ Unions } & \multirow{2}{*}{$\begin{array}{l}\text { Together } \\
\text { w/spill. }\end{array}$} & \multirow{2}{*}{$\begin{array}{l}\text { Percentage } \\
\text { Explained }\end{array}$} \\
\hline Measures & Changes & $\begin{array}{c}\text { no } \\
\text { spill. }\end{array}$ & w/spill. & $\begin{array}{c}\text { no } \\
\text { spill. }\end{array}$ & w/spill. & & \\
\hline \multicolumn{8}{|l|}{ A: $1979-1988$} \\
\hline $90-10$ & 0.333 & 0.141 & 0.195 & 0.007 & 0.007 & 0.201 & $60 \%$ \\
\hline $90-50$ & 0.087 & 0.008 & 0.007 & 0.011 & 0.014 & 0.020 & $23 \%$ \\
\hline $50-10$ & 0.246 & 0.133 & 0.188 & -0.004 & -0.007 & 0.181 & $74 \%$ \\
\hline Std(log wages) & 0.093 & 0.017 & 0.039 & 0.003 & 0.004 & 0.045 & $48 \%$ \\
\hline Gini & 0.050 & 0.011 & 0.020 & 0.002 & 0.003 & 0.024 & $48 \%$ \\
\hline Theil & 0.039 & 0.009 & 0.016 & 0.002 & 0.004 & 0.020 & $52 \%$ \\
\hline \multicolumn{8}{|l|}{ B: $1988-2000$} \\
\hline $90-10$ & 0.045 & 0.003 & -0.003 & 0.003 & 0.007 & 0.004 & $9 \%$ \\
\hline $90-50$ & 0.087 & 0.002 & 0.002 & 0.005 & 0.010 & 0.012 & $14 \%$ \\
\hline $50-10$ & -0.042 & 0.001 & -0.004 & -0.002 & -0.003 & -0.008 & $20 \%$ \\
\hline Std(log wages) & 0.024 & 0.001 & -0.001 & 0.001 & 0.003 & 0.003 & $11 \%$ \\
\hline Gini & 0.021 & 0.001 & 0.000 & 0.001 & 0.003 & 0.003 & $13 \%$ \\
\hline Theil & 0.027 & 0.001 & 0.000 & 0.001 & 0.004 & 0.004 & $14 \%$ \\
\hline \multicolumn{8}{|l|}{$C: 2000-2017$} \\
\hline $90-10$ & 0.110 & -0.014 & -0.026 & 0.003 & 0.007 & -0.022 & $-20 \%$ \\
\hline $90-50$ & 0.102 & 0.001 & 0.002 & 0.005 & 0.011 & 0.013 & $13 \%$ \\
\hline $50-10$ & 0.008 & -0.015 & -0.028 & -0.002 & -0.004 & -0.035 & - \\
\hline Std(log wages) & 0.047 & -0.002 & -0.005 & 0.001 & 0.003 & -0.002 & $-5 \%$ \\
\hline Gini & 0.030 & -0.001 & -0.002 & 0.001 & 0.002 & 0.001 & $2 \%$ \\
\hline Theil & 0.034 & 0.000 & -0.002 & 0.001 & 0.003 & 0.001 & $4 \%$ \\
\hline \multicolumn{8}{|l|}{ D: $1979-2017$} \\
\hline $90-10$ & 0.488 & 0.130 & 0.166 & 0.013 & 0.021 & 0.184 & $38 \%$ \\
\hline $90-50$ & 0.276 & 0.011 & 0.010 & 0.021 & 0.036 & 0.046 & $17 \%$ \\
\hline $50-10$ & 0.212 & 0.119 & 0.156 & -0.008 & -0.014 & 0.138 & $65 \%$ \\
\hline Std(log wages) & 0.163 & 0.017 & 0.034 & 0.005 & 0.011 & 0.045 & $28 \%$ \\
\hline Gini & 0.102 & 0.011 & 0.019 & 0.004 & 0.009 & 0.027 & $27 \%$ \\
\hline Theil & 0.101 & 0.009 & 0.015 & 0.005 & 0.011 & 0.026 & $26 \%$ \\
\hline
\end{tabular}

Note: Column (1) shows the raw changes in inequality measures. Each subsequent column corresponds to a different counterfactual with either minimum wages or unionization turned back to their base period value. Columns (2) and (3) show the contribution of minimum wage changes without ("tail-pasting" only) and with spillover effects. Likewise, columns (4) and (5) show the contribution of changes in unionization without ("shiftshare" effect only) and then with spillover effects (threat effects). Column (6) shows the contribution of changes in both the minimum wage and unionization (including spillover effects). Column (7) shows how much of the overall change (column 1) can be explained by institutional change (column 6). 